\title{
Article \\ Performance Evaluation of Sustainable Concrete Comprising Waste Polypropylene Food Tray Fibers and Palm Oil Fuel Ash Exposed to Sulfate and Acid Attacks
}

\author{
Hossein Mohammadhosseini ${ }^{1, *(D)}$, Rayed Alyousef ${ }^{2, *(D)}$, Shek Poi Ngian ${ }^{1}$ and Mahmood Md. Tahir ${ }^{1}$ \\ 1 Institute for Smart Infrastructure and Innovative Construction (ISIIC), School of Civil Engineering, \\ Universiti Teknologi Malaysia (UTM), Skudai 81310, Malaysia; shekpoingian@utm.my (S.P.N.); \\ mahmoodtahir@utm.my (M.M.T.) \\ 2 Department of Civil Engineering, Prince Sattam Bin Abdulaziz University, Al-Kharj 16273, Saudi Arabia \\ * Correspondence: mhossein@utm.my (H.M.); r.alyousef@psau.edu.sa (R.A.)
}

Citation: Mohammadhosseini, H.; Alyousef, R.; Poi Ngian, S.; Tahir, M.M. Performance Evaluation of Sustainable Concrete Comprising Waste Polypropylene Food Tray Fibers and Palm Oil Fuel Ash Exposed to Sulfate and Acid Attacks. Crystals 2021, 11, 966. https:// doi.org/10.3390/cryst11080966

Academic Editors: Yifeng Ling, Chuanqing Fu, Peng Zhang and Peter Taylor

Received: 31 July 2021

Accepted: 14 August 2021

Published: 16 August 2021

Publisher's Note: MDPI stays neutral with regard to jurisdictional claims in published maps and institutional affiliations.

Copyright: (c) 2021 by the authors. Licensee MDPI, Basel, Switzerland. This article is an open access article distributed under the terms and conditions of the Creative Commons Attribution (CC BY) license (https:// creativecommons.org/licenses/by/ $4.0 /)$.

\begin{abstract}
Sulfate and acid attacks cause material degradation, which is a severe durability concern for cementitious materials. The performance of concrete composites comprising waste plastic food trays (WPFTs) as low-cost fibers and palm oil fuel ash (POFA) exposed to acid and sulfate solutions has been evaluated in an immersion period of 12 months. In this study, visual assessment, mass variation, compressive strength, and microstructural analyses are investigated. For ordinary Portland cement (OPC), six concrete mixtures, including $0-1 \%$ WPFT fibers with a length of $20 \mathrm{~mm}$, were prepared. In addition, another six mixtures with similar fiber dosages were cast, with $30 \%$ POFA replacing OPC. It was discovered that adding WPFT fibers and POFA to concrete reduced its workability. POFA concrete mixes were found to have higher long-term compressive strength than OPC concrete mixes cured in water. As a result of the positive interaction between POFA and WPFT fibers, both the crack formation and spalling of concrete samples exposed to acid and sulfate solutions were reduced, as was the strength loss. The study's findings show that using WPFT fibers combined with POFA to develop a novel fiber-reinforced concrete subjected to chemical solutions is technically and environmentally feasible. WPFT fibers have a significant protective effect on concrete against chemical attacks.
\end{abstract}

Keywords: sustainability; concrete composites; durability; sulfate and acid attacks; WPFT fibers

\section{Introduction}

Over the past few decades, global recycling and energy recovery rates have steadily grown, consequently reducing contributions to landfill sites. Around the world, the rate of landfilling varies greatly. Plastics have become an essential and fundamental part of our lives in numerous shapes and types, and the use of plastic has progressively increased. Global plastic manufacturing reached about 288 million tons in 2012 [1]. Approximately half of this amount was spent on one-time consumable commercial products, which have contributed significantly to the rise of plastic-related waste. Furthermore, Wu and Montalvo [2] stated that plastics contribute an ever-increasing quantity to the solid waste stream, owing to their wide variety of uses. Besides, because computable information on waste plastic manufacturing is usually maintained in-house and accomplished on a business-to-business basis, it is rarely made public. According to Plastics Europe, European countries produce 25 million tons of waste plastic annually. Eriksen et al. [3] reported in 2014 that only $29.7 \%$ of waste was effectively recycled, with about $39.5 \%$ being used as reutilization and energy resources, and 30.8\% being disposed of. Hearn and Ballard [4] stated that the generated waste plastics are non-biodegradable and can remain in nature for decades or centuries. Additionally, chemical reactions in some waste plastics can emit hazardous chemicals, contaminating the air, soil, and underground waters. Consequently, the generation of plastic wastes from any source is seen as a significant ecological problem. 
Food packaging has changed substantially since the nineteenth century in response to global innovations and client needs. In this regard, Blanco [5] pointed out that over the last three decades, the utilization of plastics in various types and forms in food packaging has grown dramatically, as these materials are available in vast amounts with lower cost, transferability, good barrier properties, and prospective utility. Silvestre et al. [6] also stated that packing contributes to about $42 \%$ of the worldwide plastic sector, which has raised from about 5 million tons in the 1950s to over 100 million tons worldwide, with the packaging industry accounting for nearly $2 \%$ of GNP in developing countries. Despite all the benefits of polymeric food packaging stated above, Martino et al. [7] discovered that most of these polymers are conventionally created with high microbial resistance and have become unsustainable for the ecosystem. Because of the increased attention to decreasing the ecological challenges connected with plastic waste discarding and recycling, several researchers have been motivated to invent new materials that are less harmful to the environment [8-10]. Based on the location and accessible technologies and equipment, postconsumer waste plastics could be attained with various methods. The recycling process is complicated, according to Hubo et al. [11], since biological particles may contaminate waste plastic food trays. Kumar et al. [12] stated that the prevention of waste plastic generation in the first place, which is directly related to public awareness, is one of the preeminent techniques to avoid the accretion of a large number of waste plastics. These strategies and attempts are similar to those targeted at the appropriate and well-organized valorization of the enormous masses of plastic waste that are undoubtedly formed daily. Thus, according to Siddique et al. [13], the first-ever option that comes to mind is mostly the dumping and burning of such wastes.

According to Almeshal et al. [14], recovering plastic wastes from pre-and postconsumer sources is one of the most popular technological advances to recycle such waste, generate new raw materials, and end the loop of plastic waste; however, due to a deficiency of equipment and technology, most of the polypropylene food trays, including several impurities, are not appropriate to send for recycling and be used as secondary raw materials. Conventional approaches to discarding the massive volume of generated plastic wastes worldwide include burning and dumping [15,16]. Consequently, a reliable waste disposal strategy is required for this form of solid waste. A mechanical or chemical mechanism creates fresh raw materials during reprocessing. Eriksen et al. [3] reported that these unique raw materials could be used in production procedures to complete the circle or be utilized in other activities, such as buildings or similar construction industries. The recycling and reprocessing of solid wastes such as plastics are critical steps toward sustainable development in modern life [17]. Household plastic wastes, particularly polypropylene type of food trays, are a dispersed and contaminated resource, causing less reused plastic and reduced potential for closed-loop recovery. Lower physicomechanical properties and governing necessities for the chemical composition of reusable plastics can limit the possibility of closed-loop recycling [18].

Furthermore, one of the sectors where a considerable amount of plastic as waste material can be utilized is the construction industry. A great deal of research has been carried out in regard to plastic waste components as aggregates and fiber constituents in concrete mixtures [19]. Construction materials, like polymeric-based fibers, formed from raw plastic components are widely available. Researchers have been interested in reused plastics from several suppliers, and various investigations on the properties of concrete made from waste plastic materials and its potential ecological impacts have been conducted [20]. Concrete in various types has been recognized in construction industries for its simplicity of manufacturing, strength, and specific durability characteristics; however, concrete elements are frequently subjected to adverse circumstances, either naturally, like sulfate-rich coastal areas and soils, or artificially, including industrial wastewater and drainage, which impact the overall efficiency of hardened concrete. Sotiriadis et al. [21] stated that concrete degrades under the influence of such harsh conditions due to chemical reactions involving ion exchange. These compounds attack the C-S-H crystals of the cement 
matrix and the formation of soluble components such as ettringite and gypsum in the concrete matrix. Due to the creation of these new products, the microstructure of the matrix changes, causing the concrete to deteriorate [22].

Sulfate attack is a severe issue that shortens the service life of concrete. Sulfates are widespread in groundwaters when they occur in sulfate-bearing rocks with sulfate mineral-rich soils. Furthermore, as revealed by Bulatovic et al. [23], seawater contains a significant amount of sulfate. Generally, the solid forms of sulfate do not enter and attack the concrete components aggressively, but sulfate ions find their way into the previous matrix and chemically react with the cement constituents when dissolved in water. In mortar and concrete, a sulfate attack results in the creation of expanding gypsum and ettringite components. Consequently, the calcium aluminate hydrate of the cement paste is primarily influenced in this case [24,25]. Aside from sulfates, which can penetrate concrete and cause severe damage, acids are yet another chemical that could also lead concrete structures to deteriorate. Acid attack is not entirely resistant to cementitious materials [26]. Hadigheh et al. [27] stated that the cement hydrate's most sensitive component is $\mathrm{Ca}(\mathrm{OH})_{2}$, but the acid could also affect the C-S-H gels in the matrix, depending on the types of acid and their concentration. Lu et al. [28] reported that acidic rains in which sulfuric acid is the primary element cause severe corrosion in concrete components. Furthermore, according to Mohammadhosseini and Tahir [29], the main consequence of sulfuric attack is gypsum, observable on the surface and linked to the volume expansion of concrete specimens that could induce tensile stress structural elements, resulting in cracking and spalling. Besides, Bankir and Sevim [30] pointed out that the accumulation of gypsum in reinforced concrete reduces the corrosion rate of rebar by sealing the outer surface of the samples if it is not washed out. Different chemical processes among cement paste and gypsum, such as the formation of calcium aluminate, can result in ettringite development with a higher quantity, leading to further specimen cracks and a reduction in the concrete compressive strength.

In addition to mechanical characteristics, fiber-reinforced concrete has shown satisfactory performance after contact with chemicals such as acid and sulfate attacks [31]. For instance, adding polypropylene (PP) fiber to concrete reduces the pre-yield toughness of reinforced concrete beams and the corrosion of steel bars [32]. Sulfate attacks on hardened concrete are among the most prevalent in terms of deterioration due to the chemical reaction among sulfate ions and the cement paste, which finally directs to the formation of ettringite and gypsum and therefore causes concrete to deteriorate [33]. Owing to the high surface free energy, the addition of PP fiber to concrete improves its resistance to magnesium sulfate and acid attacks, as well as good resistance to crack formation by minimizing cracks in the interfacial transition zones (ITZ) [34]. Consequently, adding fibers to concrete enhances its mechanical properties and improves its ability to resist chemical attacks. Bolat et al. [35] reported that several strategies could be used to develop the durability of concrete structures. For instance, admixtures improve the strength and show superior durability performance in concrete by generating a dense matrix by giving a well-graded particle size dissemination for reducing the entry of severe components into the concrete. These procedures have little effect on the ductility of concrete [36], where a study investigated the use of WPFT fiber and POFA ashes in the development of concrete composites and evaluated the combination of these materials on the performance of concrete under sulfate and acid attacks. Concrete specimens were immersed in water, $10 \% \mathrm{MgSO}_{4}$, and $5 \%$ $\mathrm{H}_{2} \mathrm{SO}_{4}$ solutions for 12 months, and concrete performance was assessed in terms of visual assessment, mass change, and variation in strength analysis. Moreover, the effects of chemical attacks on concrete microstructure were examined by scanning electron microscopy (SEM). In addition, the use of waste materials in concrete, such as plastic waste, contributes to the reduction and environmental protection of generated waste. 


\section{Experimental Program \\ 2.1. Materials}

In this study, ordinary Portland cement (type I) was utilized and met the ASTM C 150-07 standards. Also, raw POFA ashes from a palm oil mill in Johor, Malaysia, were collected. The ash was dried and sieved at a temperature of $100 \pm 5^{\circ} \mathrm{C}$ to remove bigger components and reduce the carbon content. For every $4 \mathrm{~kg}$ of raw ashes, fine particles lesser than $150 \mu \mathrm{m}$ were processed for grinding in a Los Angeles abrasion device for around $2 \mathrm{~h}$. The acquired POFA met the requirements of BS 3892 part 1 of 1992, and it may be classified as class $\mathrm{C}$ and F according to ASTM C618-15. Table 1 lists the physical characteristics and chemical compositions of the OPC and POFA.

Table 1. Physical properties and chemical composition of the OPC and POFA.

\begin{tabular}{|c|c|c|c|c|c|c|c|c|c|c|}
\hline \multirow{2}{*}{ Material } & \multicolumn{4}{|c|}{ Physical Properties } & \multicolumn{6}{|c|}{ Chemical Composition (\%) } \\
\hline & Specific Gravity & Blaine Fineness & $\mathrm{SiO}_{2}$ & $\mathrm{Al}_{2} \mathrm{O}_{3}$ & $\mathrm{Fe}_{2} \mathrm{O}_{3}$ & $\mathrm{CaO}$ & $\mathrm{MgO}$ & $\mathrm{K}_{2} \mathrm{O}$ & $\mathrm{SO}_{3}$ & LOI \\
\hline OPC & 3.15 & 3990 & 20.4 & 5.2 & 4.19 & 62.4 & 1.55 & 0.005 & 2.11 & 2.36 \\
\hline POFA & 2.42 & 4930 & 62.6 & 4.65 & 8.12 & 5.7 & 3.52 & 9.05 & 1.16 & 6.25 \\
\hline
\end{tabular}

In this work, clean and dry natural river sand with a maximum size of $4.75 \mathrm{~mm}$ was used as fine aggregate with a 2.3 fineness modulus and 2.6 specific gravity value and water absorption of $0.7 \%$. Also, crushed granite passed through a $10 \mathrm{~mm}$ sieve with a 2.7 specific gravity and water absorption of $0.5 \%$ was utilized as a coarse aggregate. Potable water was used for mixing and curative reasons. A constant dosage of a polymeric superplasticizer was added to balance the flowability of fresh concrete. In addition, the fibers used in this research were fabricated from a polypropylene form of post-consumer waste food trays. The trays of different sizes and forms were recovered as post-consumer waste and washed with water to remove any contaminants that could impair the characteristics of the concrete, as shown in Figure 1a. The hand-cutting operation was performed with scissors to generate consistent sheets. To be employed in the main experiments as fibers, the unpolluted plastic strips from waste food trays were cut to a uniform width of $2 \mathrm{~mm}$, thickness of $0.3 \mathrm{~mm}$, and $20 \mathrm{~mm}$ length (Figure $1 \mathrm{~b}, \mathrm{c}$ ). The fundamental features of the waste polypropylene food tray fibers are listed in Table 2.
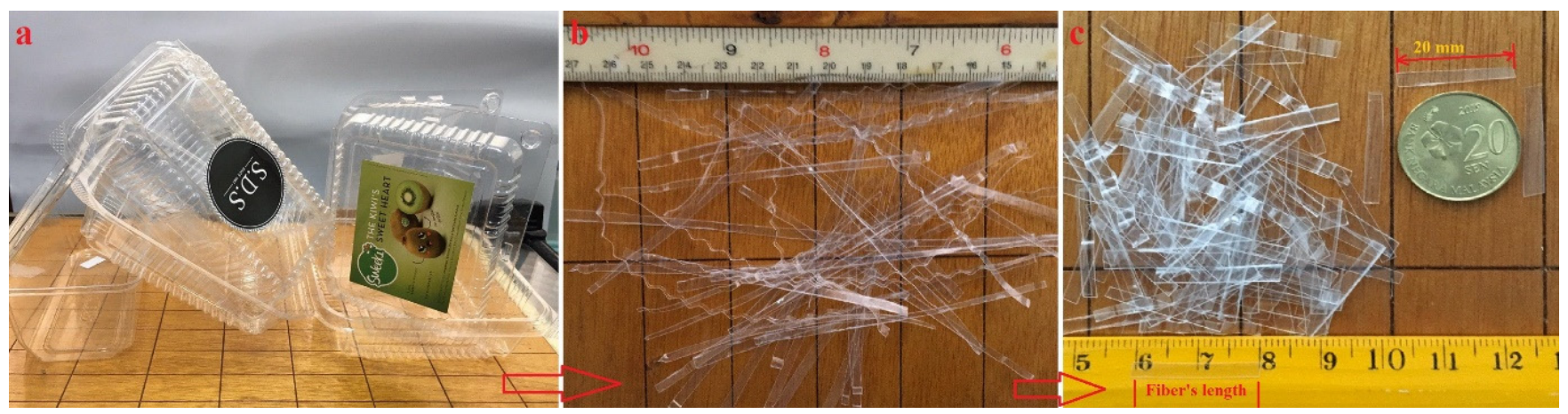

Figure 1. (a) Post-consumer waste plastic food trays, (b) fabricated fibers and (c) WPFT fibers used in this study.

Table 2. Typical characteristics of the fabricated WPFT fibers used in this study.

\begin{tabular}{ccccccc}
\hline Plastic Type & Strand Shape & $\begin{array}{c}\text { Dimension } \\
(\mathbf{W} \times \mathbf{L})(\mathbf{m m})\end{array}$ & $\begin{array}{c}\text { Density Range } \\
\left(\mathbf{g} / \mathbf{c m}^{3}\right)\end{array}$ & $\begin{array}{c}\text { Thickness } \\
(\mathbf{m m})\end{array}$ & $\begin{array}{c}\text { Tensile } \\
\text { Strength (MPa) }\end{array}$ & Elongation $(\mathbf{\%})$ \\
\hline Polypropylene & Rectangular & $2 \times 20$ & 0.94 & 0.3 & 550 & $7-10$ \\
\hline
\end{tabular}




\subsection{Formulation of the Experimental Prototype}

Table 3 shows various formulations of the experimental prototype. The DOE concrete mix design approach was used in this research, using a water/binder $(\mathrm{w} / \mathrm{b})$ ratio of 0.49 . In total, twelve mixes with varying fiber dosages were made, with a control batch (B1) being cast without the addition of WPFT fibers and POFA. Two groups of concrete mixtures, namely, OPC and POFA-based, were made with the WPFT fiber dosages of $0,0.2,0.4,0.6$, 0.8 , and $1.0 \%$ in a total of 12 batches. In the POFA-based mixtures, POFA replaced OPC by $30 \%$.

Table 3. The proportions of the different concrete mixtures.

\begin{tabular}{|c|c|c|c|c|c|c|c|}
\hline Mix & $\begin{array}{l}\text { Cement } \\
\left(\mathrm{kg} / \mathrm{m}^{3}\right)\end{array}$ & $\begin{array}{c}\text { POFA } \\
(\%)\end{array}$ & $\begin{array}{l}\text { POFA } \\
\left(\mathrm{kg} / \mathrm{m}^{3}\right)\end{array}$ & $\begin{array}{l}\text { Water } \\
\left(\mathrm{kg} / \mathrm{m}^{3}\right)\end{array}$ & $\begin{array}{c}\text { Fine Aggregate } \\
\left(\mathrm{kg} / \mathrm{m}^{3}\right)\end{array}$ & $\begin{array}{c}\text { Coarse Aggregate } \\
\left(\mathrm{kg} / \mathrm{m}^{3}\right)\end{array}$ & $\begin{array}{l}V_{f} \\
(\%)\end{array}$ \\
\hline B1 & 445 & - & - & 220 & 830 & 865 & - \\
\hline B2 & 445 & - & - & 220 & 830 & 865 & 0.2 \\
\hline B3 & 445 & - & - & 220 & 830 & 865 & 0.4 \\
\hline B4 & 445 & - & - & 220 & 830 & 865 & 0.6 \\
\hline B5 & 445 & - & - & 220 & 830 & 865 & 0.8 \\
\hline B6 & 445 & - & - & 220 & 830 & 865 & 1.0 \\
\hline B7 & 312 & 30 & 133 & 220 & 830 & 865 & - \\
\hline B8 & 312 & 30 & 133 & 220 & 830 & 865 & 0.2 \\
\hline B9 & 312 & 30 & 133 & 220 & 830 & 865 & 0.4 \\
\hline B10 & 312 & 30 & 133 & 220 & 830 & 865 & 0.6 \\
\hline B11 & 312 & 30 & 133 & 220 & 830 & 865 & 0.8 \\
\hline B12 & 312 & 30 & 133 & 220 & 830 & 865 & 1.0 \\
\hline
\end{tabular}

\subsection{Testing Methods}

Concrete cubes of a $100 \mathrm{~mm}$ size were cast for the entire experimental work in accordance with the specifications of BS EN 12390-2: 2009 and BS EN 12390-3: 2009 at various curing periods up to 12 months. Chemical immersion experiments were utilized in this research work to investigate the performance of concrete composites comprising WPFT fibers and POFA against magnesium sulfate and sulfuric acid attacks. Using scanning electron microscopy (SEM), microstructural investigation of several concrete mixtures was undertaken to evaluate the morphological and degradation mechanisms. Overall, 36 concrete cubes of a $100 \mathrm{~mm}$ size were cast and coated with plastic to minimize fast vaporization for each test. The samples were then remolded after 24 hours and submerged in water for 28 days to cure. Afterward, the samples were withdrawn, wiped dry, and weighed to the nearest $0.1 \mathrm{~g}$ with an electronic weighing balance, recording the initial weight with the succeeding weight throughout the exposure period. Next, the concrete cubes were immersed in $10 \% \mathrm{MgSO}_{4}$ and $5 \% \mathrm{H}_{2} \mathrm{SO}_{4}$ solutions for the sulfate and acid resistance tests.

The concrete sample cubes were entirely submerged in the chemical solutions for 12 months, and the $\mathrm{pH}$ values of the solutions changed quickly in both tests. Nevertheless, the $\mathrm{pH}$ for the sulfate resistance test was restricted to a concentrated value of 8.5 and 2.5 for the acid solution. The $\mathrm{pH}$ was controlled through refreshing the solutions and was then maintained constantly during the immersion duration. No standardized approach is currently in place to test concrete resistance against sulfuric acid and sulfate assaults. Furthermore, the testing techniques of ASTM C1012-15, ASTM C267-01-2012, and ASTM C452-15 guide testing the chemical resistance of mortar and polymer concrete. Consequently, following the standard specifications and the current literature, the concentration levels of $10 \%$ and $5 \%$ were selected in this study for the magnesium sulfate and sulfuric acid, respectively.

At the end of the exposure period (12 months), to evaluate the consequences of chemical attacks on the performance of the concrete samples, the samples were taken from the testing tanks and cleaned with plain water, then dried in a testing room at 
ambient temperature for about 30 minutes. After the specimens had sufficiently dried, visual inspection was carried out to observe the degradation degree for each mixture after 12 months of exposure in the $\mathrm{MgSO}_{4}$ and $\mathrm{H}_{2} \mathrm{SO}_{4}$ solutions. The evaluation considered the specimen edges, texture, color, size, and geometry. After that, the average masses of specimens for each group were measured to calculate the variation in the mass by following Equation (1):

$$
M L_{t}=\frac{M_{t}-M_{i}}{M_{i}} \times
$$

where $M_{t}$ is the average mass of samples after 12 months exposure to chemical solutions (gr), $M_{i}$ is the original mass earlier absorption (gr), and $M L_{t}$ is the cumulative mass loss after 12 months of exposure.

An evaluation of the strength loss factor (SLF \%) after 12 months of exploration was carried out to indicate the level of deterioration in concrete mixtures in terms of reduction in compressive strength, and the calculation was made with the following formula (Equation (2)):

$$
S L F=\frac{F_{c w}-F_{c S}}{F_{c w}} \times 100 \%
$$

where SLF indicates the percentage of loss in compressive strength of concrete cubes exposed to $\mathrm{H}_{2} \mathrm{SO}_{4}$ and $\mathrm{MgSO}_{4}$ solutions for 12 months, $F_{c w}$ is the obtained strength values of concrete specimens after 12 months cured in plain water, and $F_{c s}$ is the residual strength of the cubic samples immersed in $\mathrm{H}_{2} \mathrm{SO}_{4}$ and $\mathrm{MgSO}_{4}$ solutions for the same period.

\section{Results and Discussion}

\subsection{Workability}

A slump test was carried out to investigate the effects of WPFT fibers on the fluidity of concrete mixtures and the results are presented in Figure 2. WPFT fiber addition led to a reduction in the slump values, with the highest slump value being $185 \mathrm{~mm}$ for the OPC control mix. Slump values of $140 \mathrm{~mm}$ and $95 \mathrm{~mm}$ were noted for mixes comprising $0.2 \%$ and $0.4 \%$ WPFT fibers, respectively. According to the ACI 211-02 standard requirements, these concrete mixtures have fluid and plastic workability and can be used in structural members with congested and regular reinforcing. A minimum slump value of $35 \mathrm{~mm}$ was measured for the mixture containing 1\% WPFT fibers. The results also demonstrate that the POFA mixes had less workability than the OPC-based mixes. Increases in the dosage of fibers had a comparable consequence on the flowability of the POFA mixtures. The slump of mixes with fiber dosages of $0,0.2,0.4,0.6,0.8$, and $1 \%$, for example, were measured as $165,115 \mathrm{~mm}, 70 \mathrm{~mm}, 55 \mathrm{~mm}, 40 \mathrm{~mm}$, and $25 \mathrm{~mm}$. Previous research has shown that the PP types of waste plastic fiber harm the workability of concrete [37]. This could be attributed to the fact that fibers with a large surface area absorb more cement paste, which causes the viscosity to rise, resulting in a lower slump value. Furthermore, the high fiber content and wide surface area of short fibers results in reduced workability [38].

\subsection{Water-cured Compressive Strength}

Cubic compressive strength testing for the concrete samples cured in plain water at various curing periods was carried out and the results are illustrated in Figure 3 . The obtained results show a decrease in the compressive strength values as the fiber volume fractions increased. Nevertheless, the reduction in strength was minor, and the strength values were within the acceptable range for structural applications. After 365 days of curing in plain water, the strengths of OPC mixtures reinforced with $0,0.2,0.4,0.6,0.8$, and $1 \%$ WPFT fibers were 48.5, 47.2, 44.8, 43.2, 39.7, and 37.4 MPa, accordingly. Generally, the modulus of elasticity of PP types of fibers ranged between 3.5-4.9 GPa, and these comparatively low values classified the PP fiber as a soft material, and the matrix was treated as a soft composite, and, therefore, caused a drop in the compressive strength of reinforced concrete specimens $[39,40]$. 


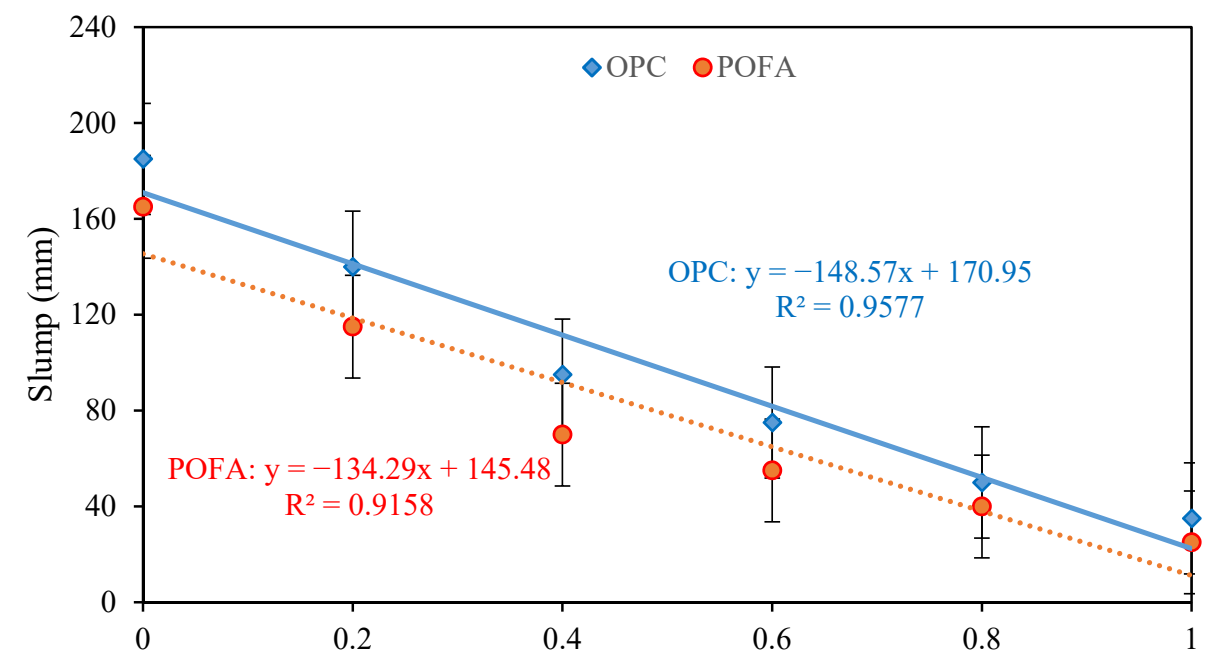

Fiber content (\%)

Figure 2. Effects of the WPFT fibers at various dosages on the slump of fresh concrete mixtures.
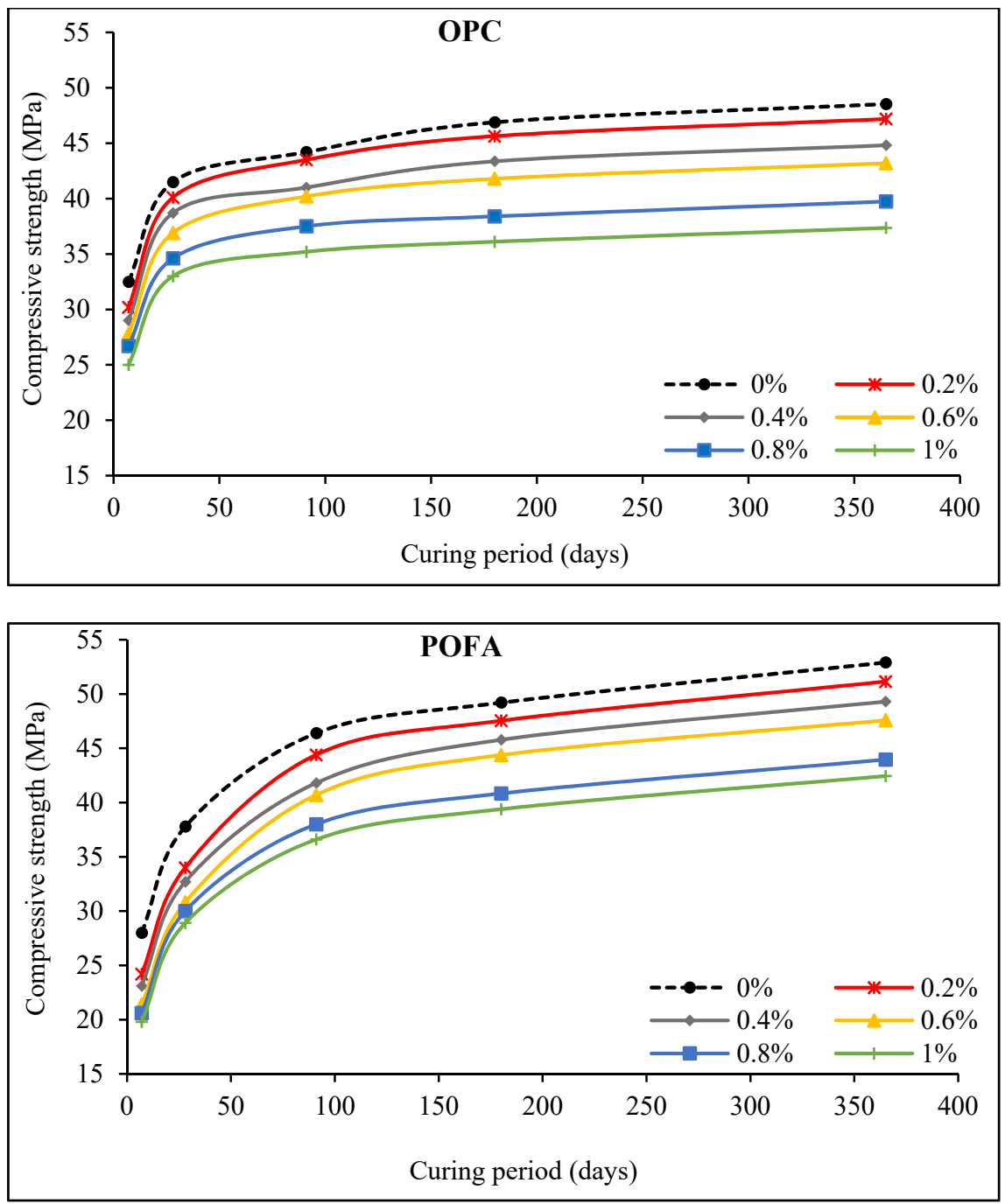

Figure 3. The variation in the water-cured compressive strength of OPC and POFA concrete mixtures containing WPFT fibers. 
Furthermore, replacing 30\% of OPC with POFA resulted in greater compressive strength values, particularly after 12 months of curing in water. The strength value for the plain POFA mix was recorded as $52.9 \mathrm{MPa}$, which is approximately $10 \%$ greater than the $48.5 \mathrm{MPa}$ compressive strength value observed for the plain OPC mixture without any fibers. The testing results showed that the POFA mixes obtained higher strength values at extended curing periods than the OPC mixes. According to Zeyad et al. [41], the higher strength of POFA mixtures could be attributed to pozzolanic activity at ultimate ages, leading to increased concrete strength by creating supplementary C-S-H gels. POFA mixtures incorporating WPFT fibers showed a similar trend to the OPC mixtures, where the inclusion of fibers and rises in fiber volume fractions resulted in slight decreases in compressive strength values [42]. After 365 days of immersion in water, the compressive strength values of POFA mixes containing $0,0.2,0.4,0.6,0.8$, and $1 \%$ WPFT fiber were 52.9 , 51.2, 49.3, 47.6, 43.9, and 42.4 MPa, respectively, as shown in Figure 3 These values were higher than those recorded for the OPC mixtures with the exact fiber dosages.

\subsection{Sulfate Attack}

\subsubsection{Visual Assessment}

The performance of cubic concrete samples immersed in the $\mathrm{MgSO}_{4}$ solution was visually inspected monthly in this investigation. The degradation scale used to assess the damage is shown in Table 4. Figure 4 depicts the appearances of specimens after 12 months of exposure, while Figure 3 depicts the deterioration degree of the OPC and POFA specimens in a $\mathrm{MgSO}_{4}$ solution for the entire exposure period. The plain OPC mix without WPFT fibers was the only mix that showed initial signs of deterioration, such as small cracks along the corners of specimens. POFA-based specimens, on the other hand, showed the first marks of degradation after three months of immersion. As shown in Figure 5, the deterioration of all specimens, with and without fibers, accelerated over time. The evolution of the OPC-based mixtures was faster than that of the samples containing $30 \%$ POFA. The specimens containing a higher dose of WPFT fibers were less severely deteriorated after 12 months of exposure than the plain concrete mixes.

Since $\mathrm{CaCO}_{3}$ and $\mathrm{Ca}(\mathrm{OH})_{2}$ are the most vulnerable elements of the cement hydrate, degradation was more intense in the OPC specimens, which have higher contents of these components. This finding suggests that sulfate-induced degradation is exacerbated by the low resistance of $\mathrm{CaCO}_{3}$ and $\mathrm{Ca}(\mathrm{OH})_{2}$ to sulfate assault, resulting in the formation of calcium sulfate $\left(\mathrm{CaSO}_{4}\right)$ [21]. The small cracks and slight deterioration that occurred at the corners of samples were the initial evidence of attack in all cases, which appears as small cracks, slow expansion of samples, and the spalling of edges. A soft white substance was also applied to the interior surfaces of the fractures. The presence of fibers was discovered to influence the degree of deterioration, as well as the progression. As can be seen, the deterioration of the specimens studied progressed more slowly in combinations reinforced with WPFT fibers, and greater fiber volume fractions showed stronger resilience. It is also worth noting that the final degree of deterioration in POFA-based combinations was lower than in the OPC mixtures for all specimens.

\subsubsection{Mass Gain}

Figure 6 depicts the variation in the masses of the concrete cube samples when immersed in a $\mathrm{MgSO}_{4}$ solution for 12 months, revealing that all mixtures gained mass after the end of the exposure period due to sulfate particle absorption by the specimens [21]. The results revealed rises in masses by 1.3 and $0.8 \%$ for the control mixes of OPC and POFA, respectively, after 12 months of exposure. The addition of WPFT fiber to the mixture, on the other hand, drastically reduced the mass increase of the specimens. The addition of fiber in the mixes appears to have contributed to the reduction in mass gain, as shown in Figure 6. For fiber contents of $0.2,0.4,0.6,0.8$, and $1 \%$, the mass gains of OPC fibrous mixes were $0.48,0.56,0.96,1.27$, and $1.57 \%$, respectively. The results also demonstrated that 
adding 30\% POFA to the fibrous composites resulted in lesser mass gains when compared to the OPC mixes when submerged in a sulfate solution.

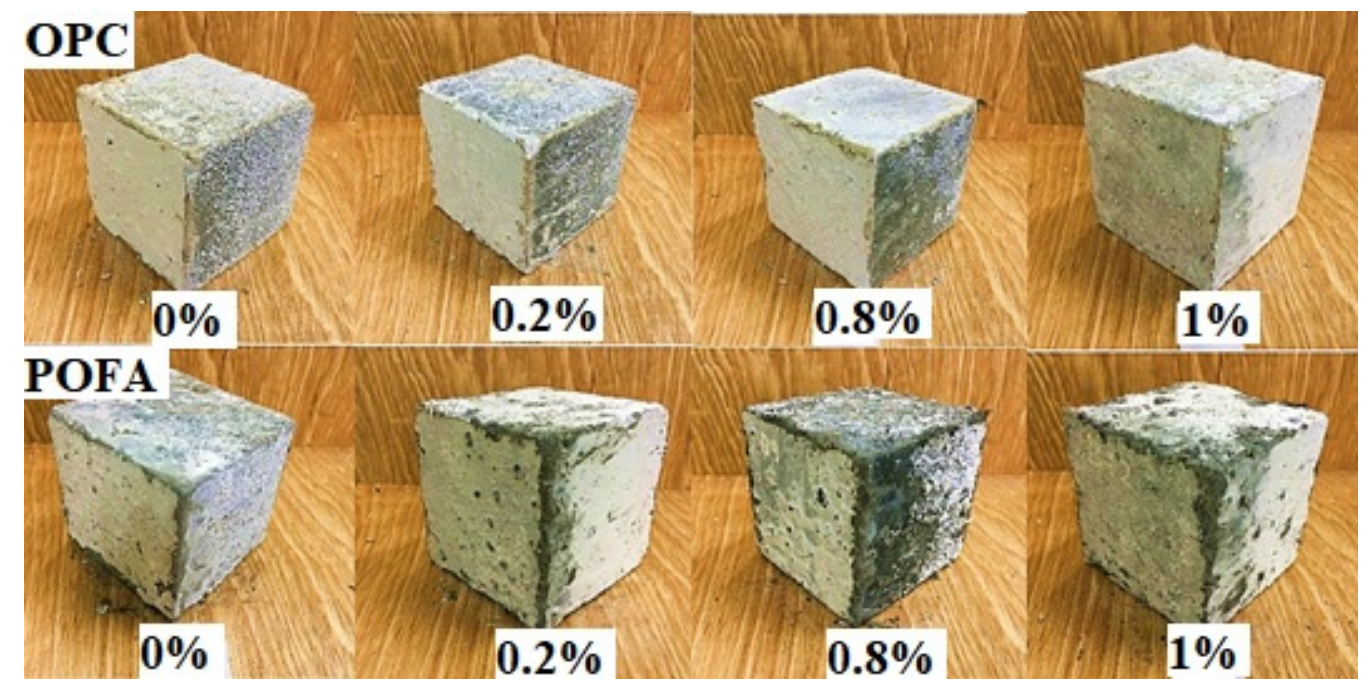

Figure 4. The appearance of concrete specimens exposed to a $\mathrm{MgSO}_{4}$ solution for 12 months.
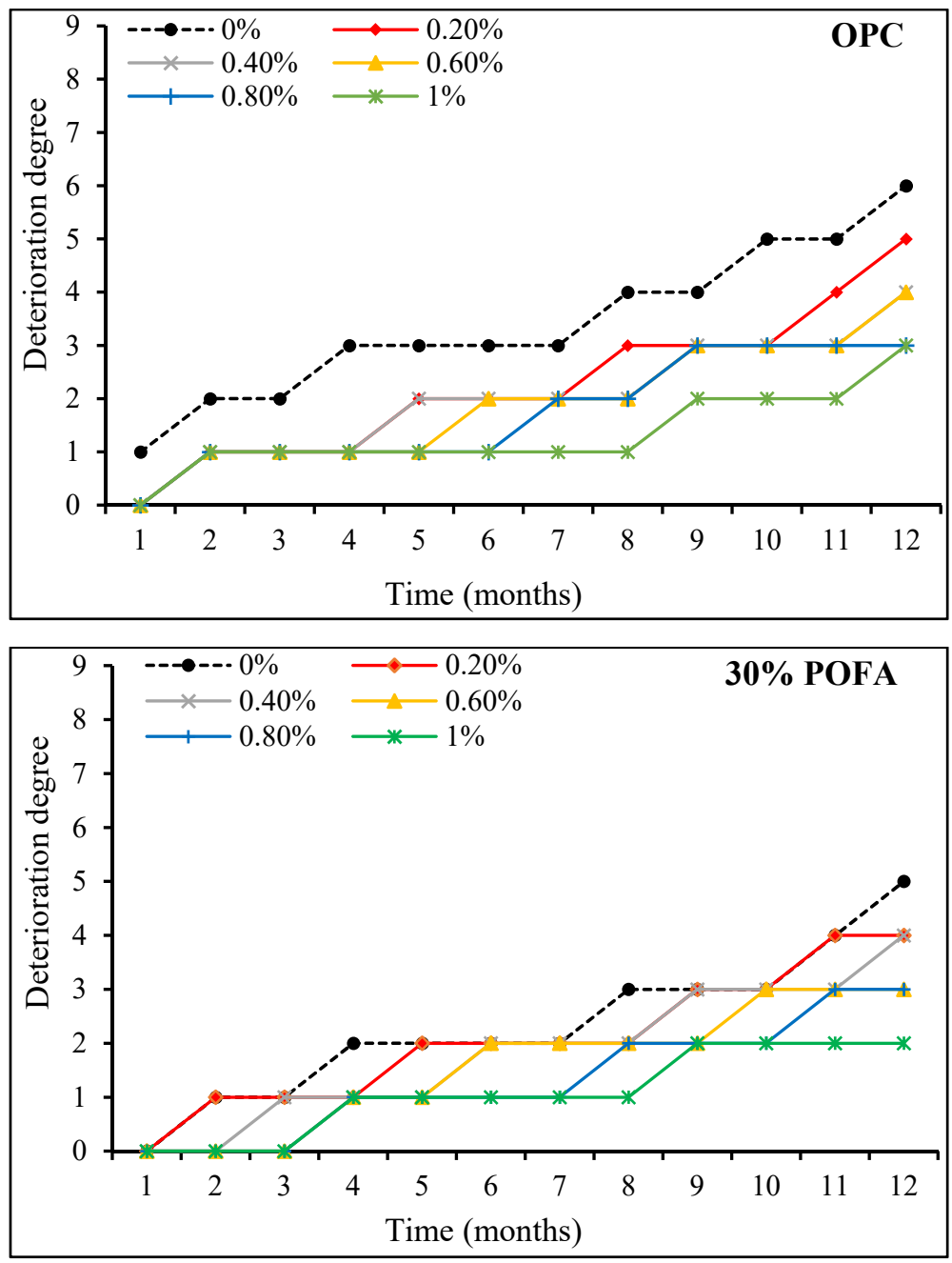

Figure 5. Deterioration degree of concrete specimens reinforced with WPFT fibers exposed to $\mathrm{MgSO}_{4}$ solutions. 
Table 4. Assumed degree of deterioration and the detected damages.

\begin{tabular}{cc}
\hline Deterioration Scale & Observed Damages \\
\hline 0 & No noticeable deterioration \\
1 & Slight deterioration at edges in the form of microcracks \\
2 & Deterioration at edges and corners \\
3 & Cracking at corners and along the edges of samples \\
4 & Severe cracks and expansion along the edges \\
6 & Widespread cracks and sample expansion \\
7 & Further expansion and side deterioration of samples \\
8 & Wide expansion and spalling \\
9 & Extensive deterioration and washout \\
\end{tabular}

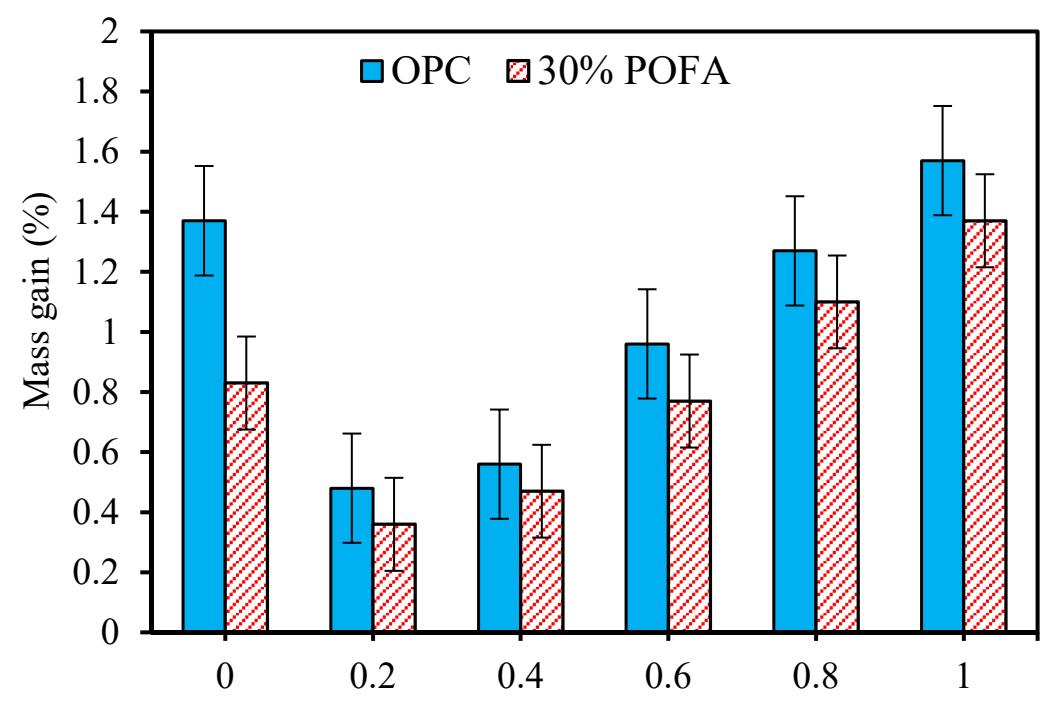

Fiber volume fraction $(\%)$

Figure 6. The effects of the WPFT fibers on the mass gain of concrete samples exposed to a $\mathrm{MgSO}_{4}$ solution.

The variations in the masses of POFA-based mixes were recorded as $0.36,0.47,0.77$, 1.1 , and $1.35 \%$ for the similar fiber levels, respectively, which indicates a gain in mass for all specimens. The development of a grid structure by fibers, which restricts particle penetration and disruption into specimens, might be attributed to the drop in the mass gain of specimens reinforced with WPFT fiber. As a result of the irregular pore arrangement of the POFA concrete and the quantity of calcium hydroxide contained in the matrix, the use of POFA in mixtures is favorable when in direct contact with a sulfate attack. Microcracks are the primary entry points for hazardous chemical ions, such as sulfate ions, into the concrete interior. The exposure of concrete specimens, either plain concrete or fiber-reinforced concrete, followed several steps, as shown in Figure 7, including: (1) initial exposure, (2) chemical reactions, (3) stress development in the concrete specimens, (4) crack formation, (5) crack development and infiltration, and (6) substantial damage in various forms. It can be seen that there were no noteworthy changes in the process of sulfate attacks amongst the plain mix and mixes reinforced with fibers, with gypsum and ettringite development producing expansion tension to cause concrete degradation [24]. The bridging action of the fiber, which arrests microcracks, reduces the permeability and spalling of the concrete significantly. Furthermore, the fibers prevent the passage of disturbance particles into specimens by arresting microcracks induced by excessive stress [25]. Consequently, the concrete mixtures comprising fibers gained less mass than conventional plain concrete. 


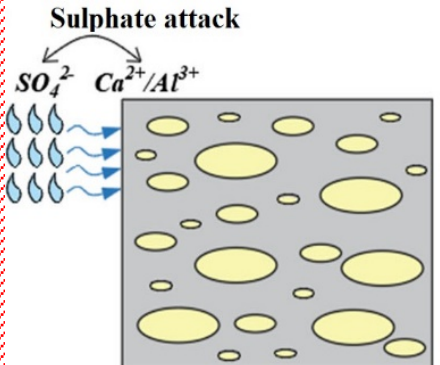

(1)

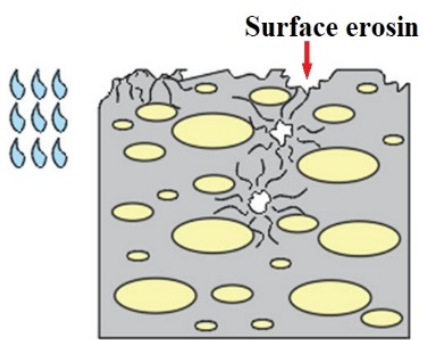

(6)

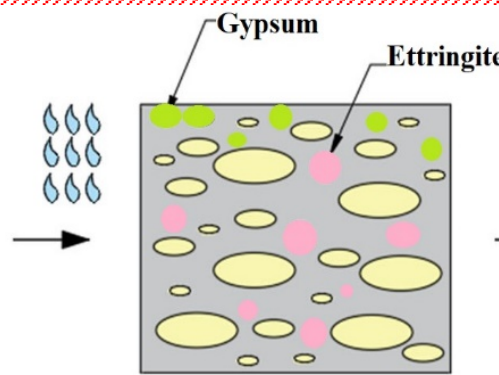

(2)

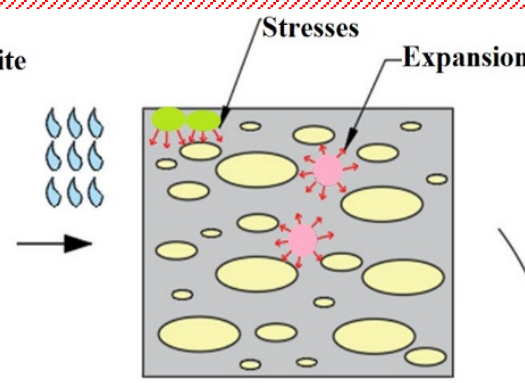

(3)

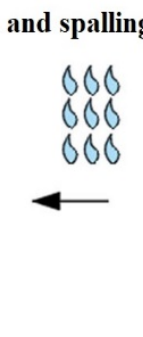

300

300

000

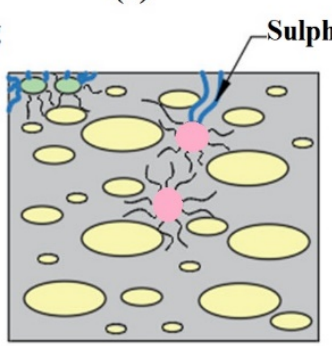

(5)
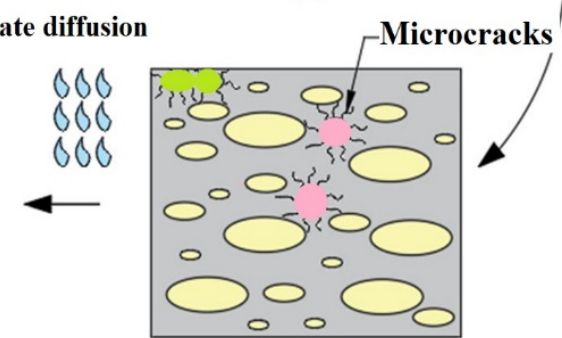

(4)

(a) Plain concrete

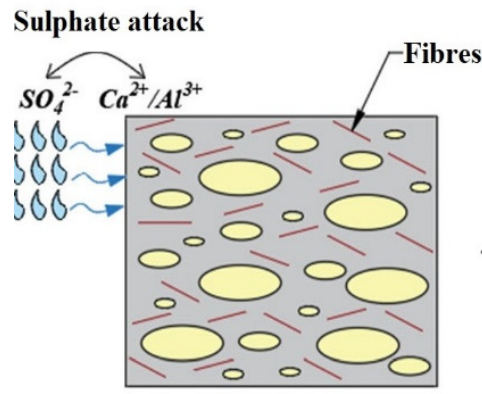

(1)

Surface erosin and spalling

(6)

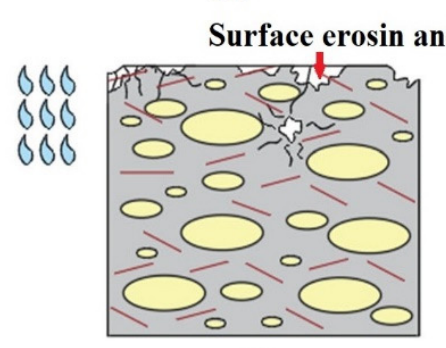

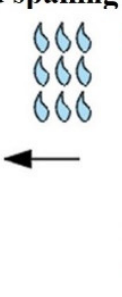

000

000

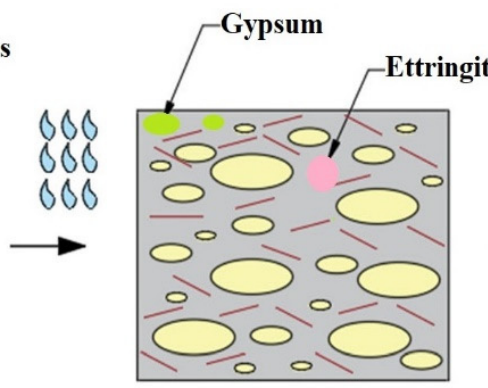

(2)

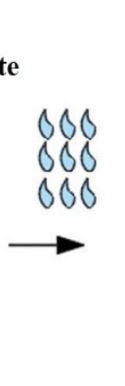

000

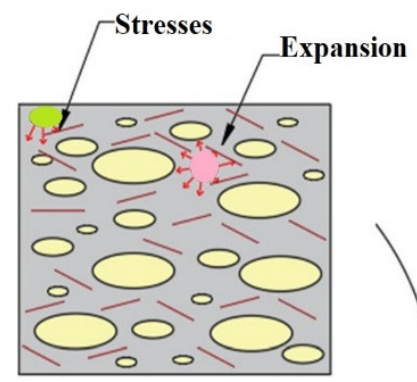

(3)

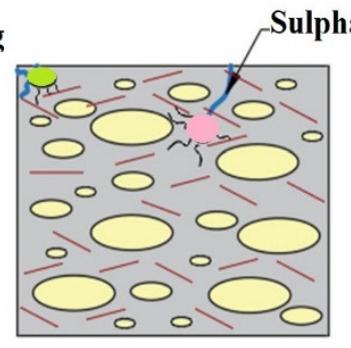

(5)
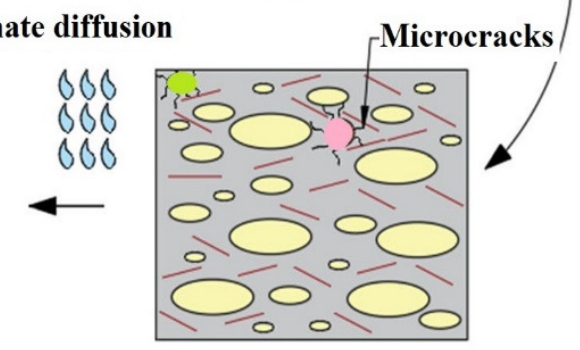

(4)

(b) Fiber-reinforced concrete

Figure 7. Diagrammatic representation of sulfate attack against (a) plain concrete and (b) fiber-reinforced concrete.

\subsubsection{Compressive Strength Loss}

Generally, concrete performance often degrades when exposed to a chemical attack and extends the immersion period, owing to physical destruction and undesirable chemical breakdown of the matrix. The inclusion of WPFT fibers improved the resistance to magnesium sulfate assault, as seen in Figure 8. After 12 months of exposure, the compressive strength of concrete mixtures exposed to sulfate attacks was evaluated, and the attained outcomes were associated with the water-cured mixes. The strength loss was described as the variation in strength among water-cured mixes and those exposed to $\mathrm{MgSO}_{4}$. The 
data in Figure 8 demonstrate that all of the blends had lost strength. When the OPC mixes were associated with those of POFA mixes, the loss was found to be greater. For example, in the OPC mixes, strength losses of 9.5, 6.3, 5.2, 9.6, 12.5, and 14.6 MPa were detected for fiber dosages of $0,0.2,0.4,0.6,0.8$, and $1 \%$, correspondingly, whereas the values of $7.5,5.7$, 3.6, 8.4, 10.7, and 12.5 MPa were recorded as strength losses for the same fiber dosages, respectively, in the POFA mixtures. It was observed that the obtained values are lower in POFA mixtures than those of OPC, which indicates the better performance of POFA concrete when exposed to chemical attacks.
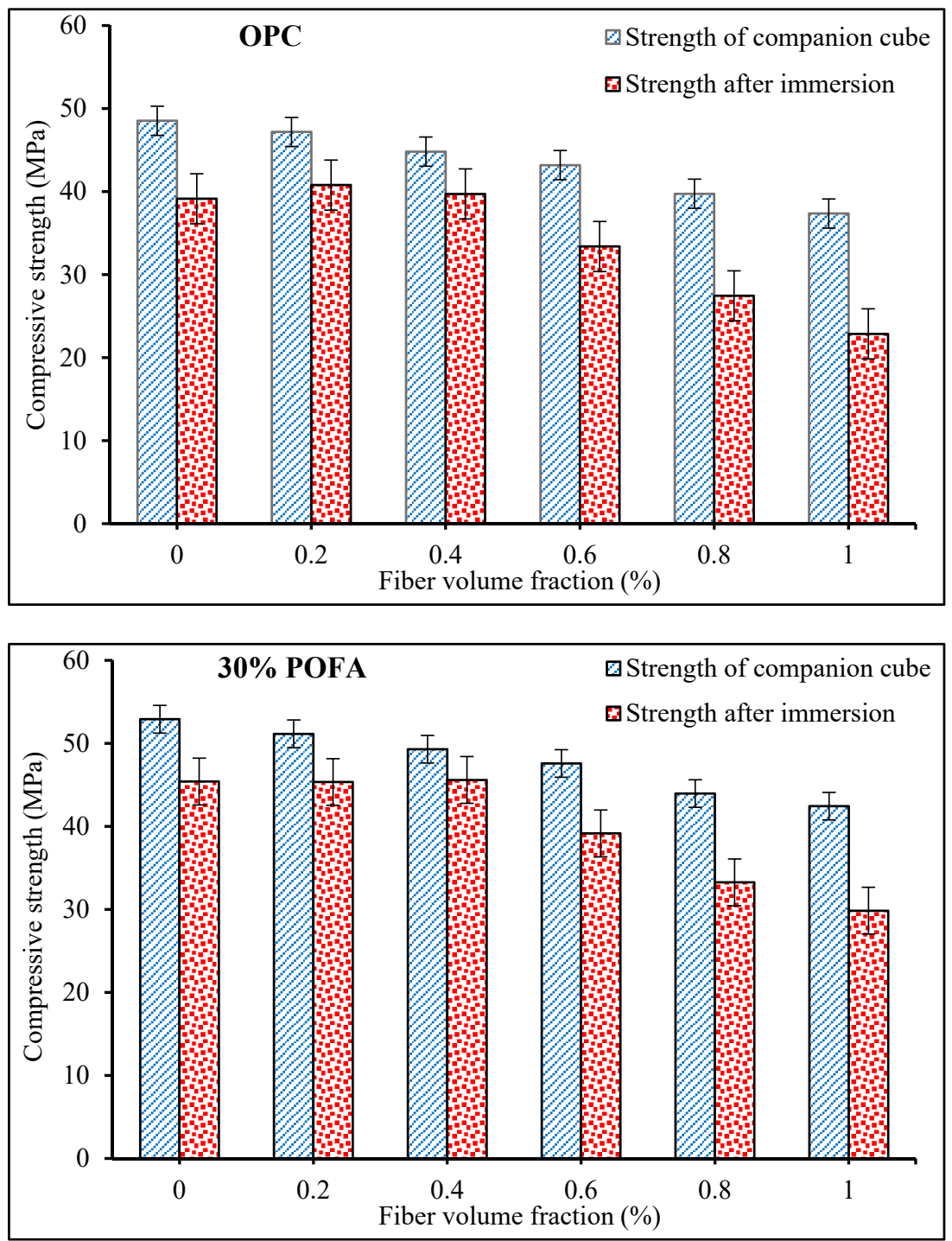

Figure 8. The variation in the 365-day compressive strength of concrete mixtures containing WPFT fibers exposed to a $\mathrm{MgSO}_{4}$ solution.

The tensile expansion strain from the development of ettringite and gypsum in matrix induces cracking and reduces the strength characteristics of concrete because of its low tensile strength. Furthermore, the magnesium attack causes calcium compounds to be released from C-S-H gels, reducing matrix stiffness and causing the specimens to break down [26]. By microscopic investigation, Honglei et al. [43] reported the formation of gypsum with double layers on the surface of the concrete samples, with only a slight amount of ettringite and monosulfate. Magnesium sulfate attack is characterized by a loss of strength and adhesion rather than cracking and expansion [44]. Furthermore, 
WPFT fibers inhibited the creation of tiny cracks and failure of specimens due to their bridging effect.

The strength loss factor (SLF), following Equation (2), was used to indicate the decline of compressive strength of concrete mixtures containing WPFT fibers after sulfate attack. Figure 9 illustrates the SLF after 12 months of exposure to the $\mathrm{MgSO}_{4}$ solution. Sulfate reactions altered all of the mixes and resulted in strength reduction. Under the same circumstances, the SLF values were much higher in the OPC fibrous composites, but the POFA specimen containing $0.4 \%$ WPFT fibers had the lowest SLFs; however, a further rise in the dosage of fibers resulted in a minor surge in the SLF values. There has been no research conducted so far on the combined effect of POFA and WPFT fibers on the sulfate resistance of concrete. Nevertheless, the study results are comparable to those of Behfarnia and Farshadfar [34] when considering the effective combination of PP fibers and pozzolanic ashes in concrete bare to chemical attacks. They reported that the combination of PP fibers and pozzolanic ashes has a significant effect on improving concrete resistance against sulfate attacks.

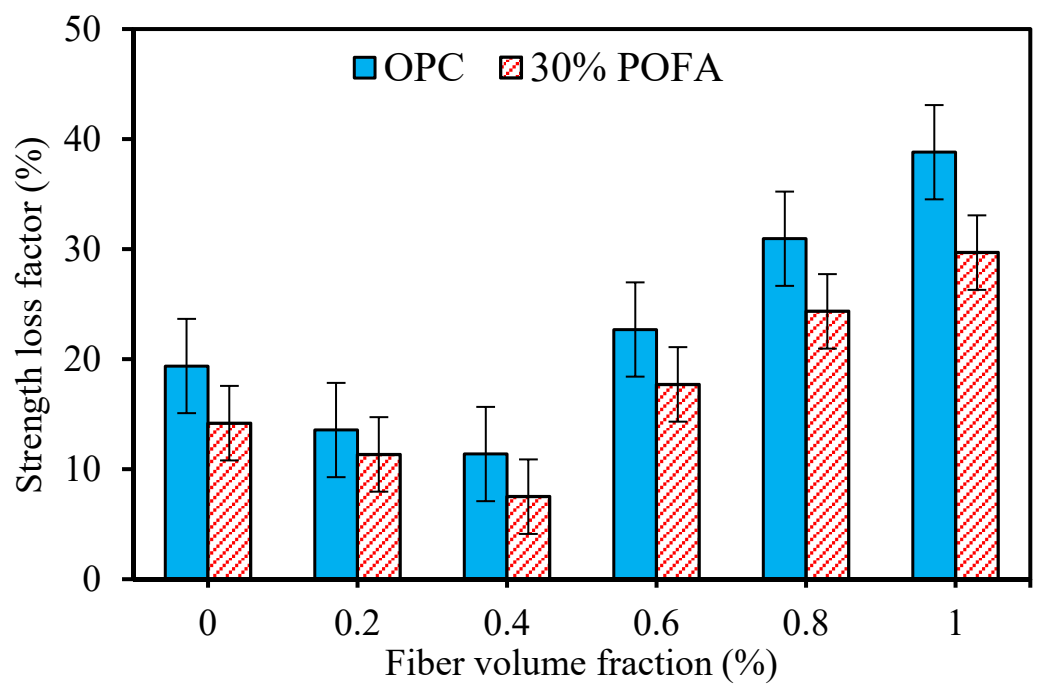

Figure 9. The effects of WPFT fibers on the strength loss factor of concrete exposed to a $\mathrm{MgSO}_{4}$ solution.

\subsection{Sulfate Attack}

\subsubsection{Visual Assessment}

The cubic samples submerged in a $\mathrm{H}_{2} \mathrm{SO}_{4}$ solution were visually inspected monthly for 12 months, similar to the sulfate resistance test. Figure 10 reveals the appearance of concrete specimens with and without WPFT fibers when exposed to the acid solution after 12 months. The initial stage in measuring the deteriorating consequence of acidic attack is commonly visual assessment through analyzing the color change, subsurface cracks, the deposition of additional components on the surface, and the spalling of specimens. As illustrated in Figure 11, the appearance and color of the concrete specimens provides a comprehensive indicator of the acid's effect on the material, regardless of whether the color reflects the original or acid-attacked surface. It was detected that the addition of WPFT fibers and POFA in concrete mixtures results in slight changes in the shape and texture of concrete samples exposed to acid, although both the plain and fiber-reinforced OPC samples were fragmented and distorted after the 12 months of exposure.

The damage shown in Figure 12 was measured using the degradation scale provided in Table 4. As illustrated in Figure 12, all specimens, with and without fibers, deteriorated faster over time. The evolution of the OPC-based mixtures was faster than that of the $30 \%$ POFA samples. For example, after 12 months of exposure, the plain OPC mix had a deterioration degree of 8 , whereas the plain POFA mix had a deterioration degree of 6 . For the entire testing period, the degree of degradation decreased as the fiber volume percentage increased. It is worth noting that a larger fiber content exhibited 
an excellently increased acid resistance and lower deterioration level. When exposed to acid, concrete specimens containing WPFT fibers showed less spalling than the control specimens without fibers.

\subsubsection{Mass Loss}

The fiber reinforcement had a considerable influence on mass loss, as demonstrated by the results. This could be ascribed to the fiber bridging action, which reduced concrete components from spalling and improved performance in an acidic environment. The mass loss vs. fiber volume fraction test results are shown in Figure 13. At the end of 12 months of exposure to $\mathrm{H}_{2} \mathrm{SO}_{4}$ solutions, all concrete specimens showed the same mass reduction behavior. The plain OPC specimens were found with a comparatively higher rate of deterioration in acidic solutions. As OPC contains about $62.5 \% \mathrm{CaO}$, it results in faster chemical reactions with acid and forms increased levels of gypsum and ettringite, which are washed out quickly and result in a higher mass rate loss spalling.

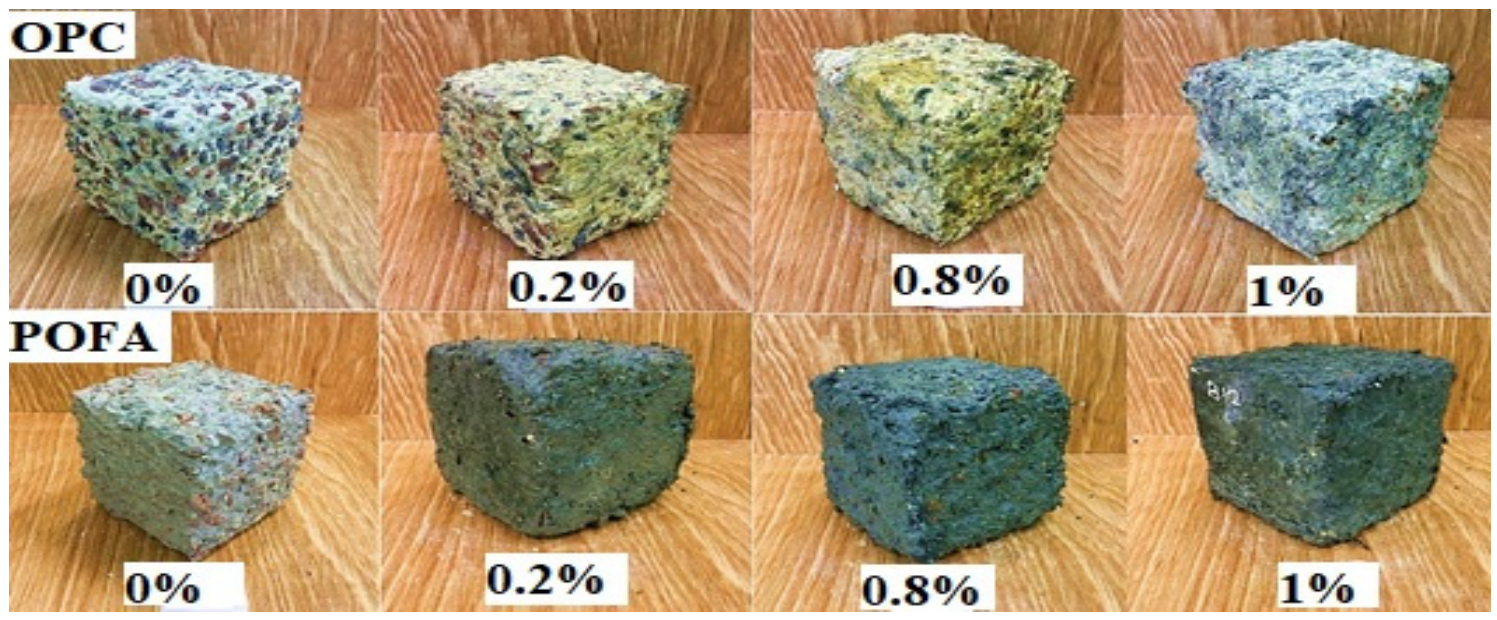

Figure 10. The appearance of various concrete specimens exposed to a $\mathrm{H}_{2} \mathrm{SO}_{4}$ solution for 12 months.

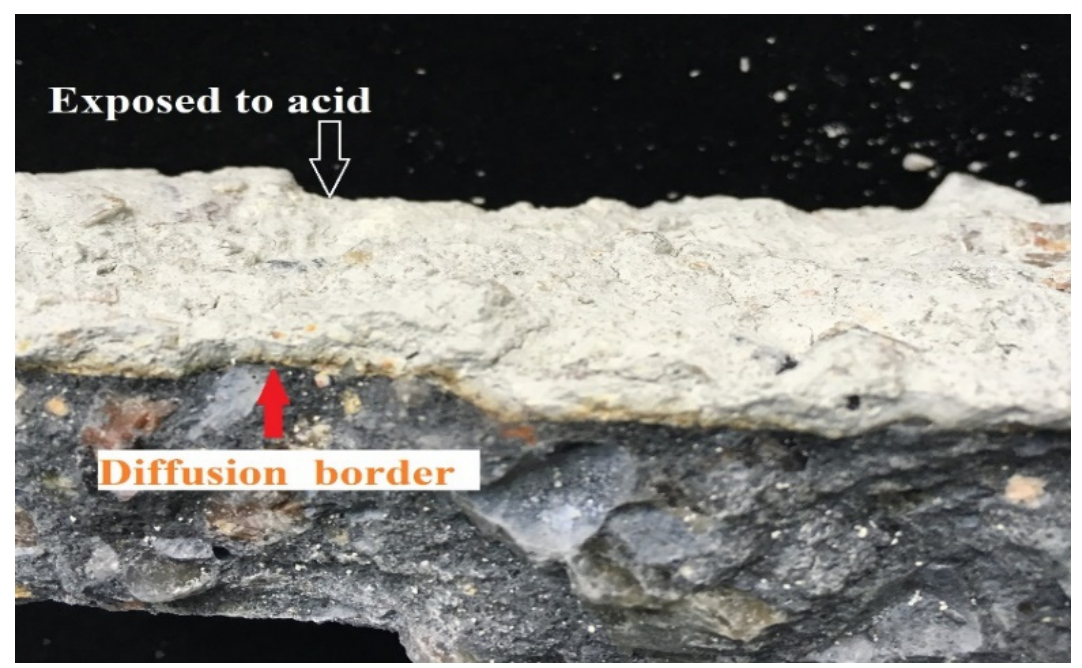

Figure 11. The effects of $\mathrm{H}_{2} \mathrm{SO}_{4}$ exposure on the texture and color of the concrete matrix. 

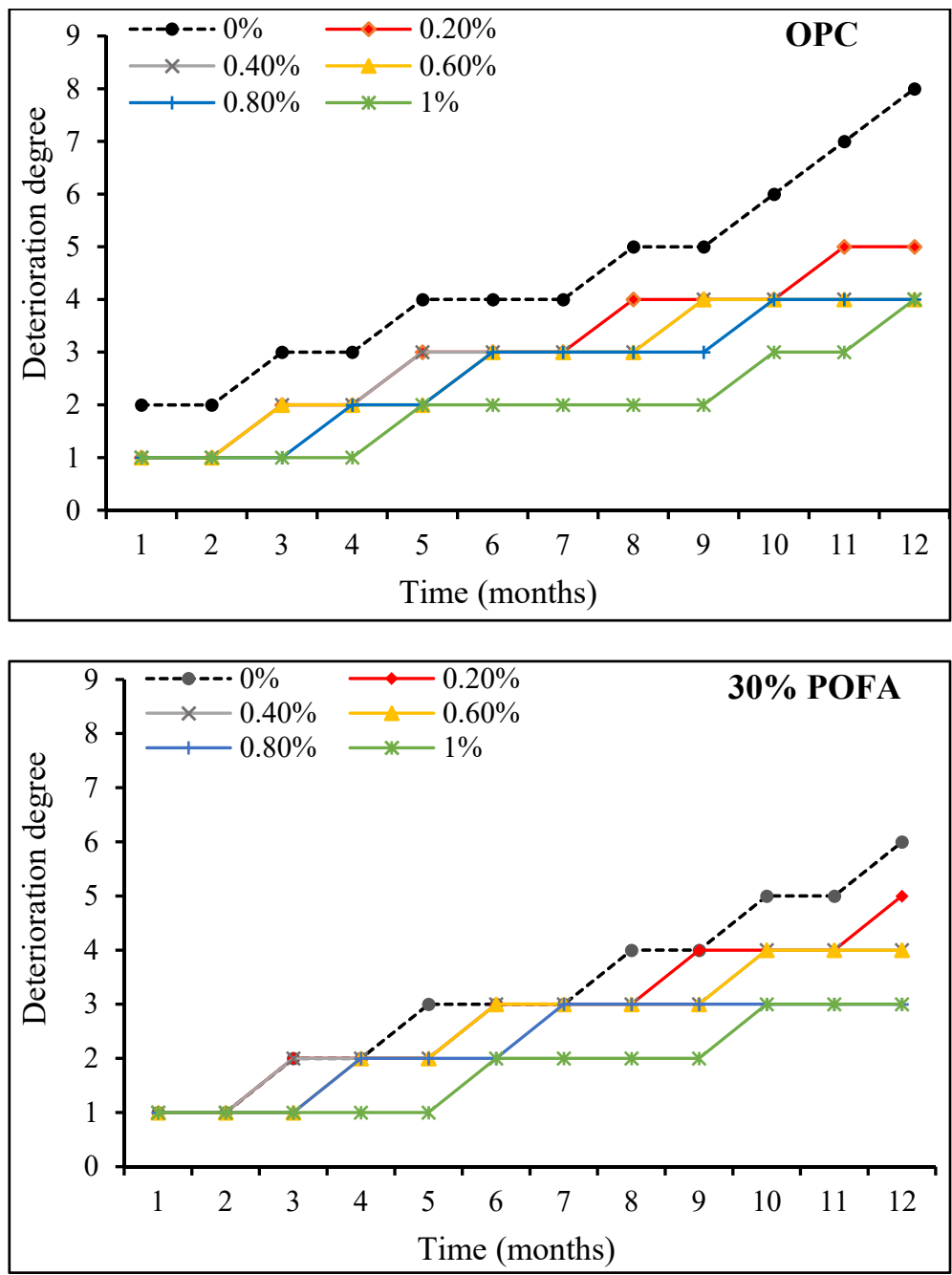

Figure 12. Deterioration degree of concrete specimens comprising WPFT fibers exposed to $\mathrm{H}_{2} \mathrm{SO}_{4}$ solutions.

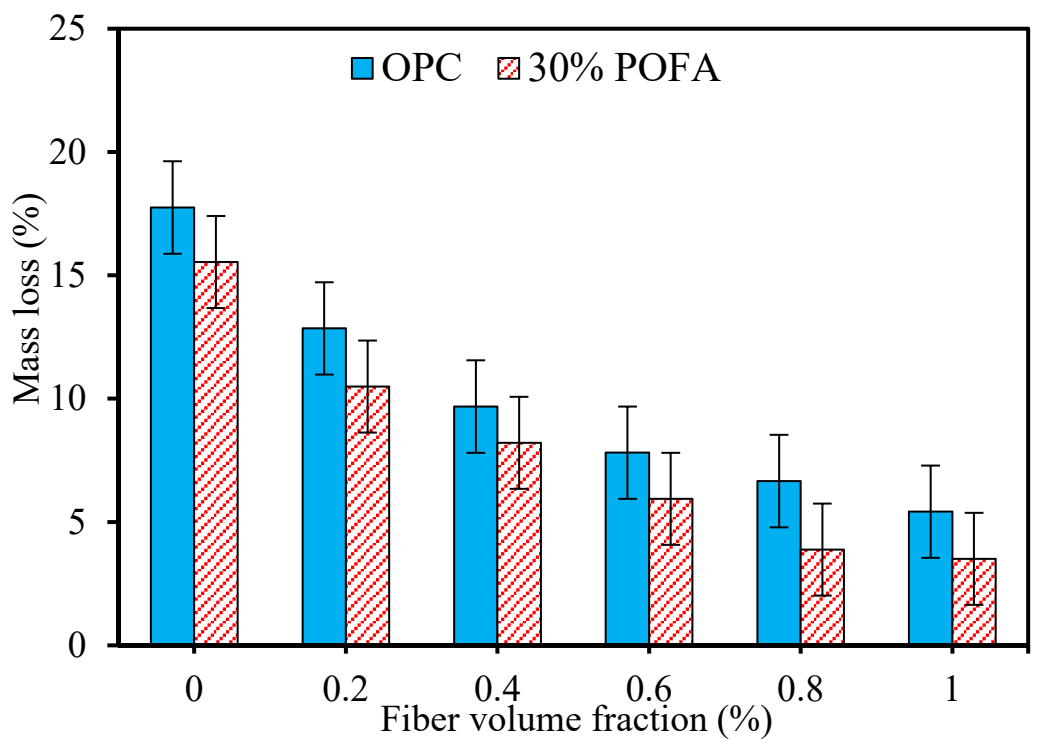

Figure 13. The effects of the WPFT fibers on the mass variation of the concrete specimens after 12 months of exposure in a $\mathrm{H}_{2} \mathrm{SO}_{4}$ solution. 
In contrast, the $\mathrm{CaO}$ content is only about $5 \%$ in POFA and provides it good acid resistance as a material in concrete production [22]. The reinforcement of concrete with WPFT fibers reduced the rate of mass loss in the OPC mixtures. In the OPC mixes reinforced with $0,0.2,0.4,0.6,0.8$, and 1\% WPFT fibers, mass loss values of 17.5, 12.7, 9.7, 7.8, 6.6, and $5.4 \%$ were recorded, respectively, indicating that the levels of mass loss in fibrous mixtures was much lower than those in plain mixtures. Acid penetrated the concrete and dissolved the cement paste binder, producing soft and soluble gypsum that subsequently interacted with $\mathrm{Ca}(\mathrm{OH})_{2}$ to form ettringite, leading to mass losses. The presence of fibers helped the concrete constituents to join via a bridging action, resulting in less breakage and deterioration of the matrix. Another harmful consequence of acid attack was the reactions among aluminate and calcium components in the OPC, leading to the formation of soluble products. These exceptionally expansive and soluble products caused internal pressures in the matrix, and microcracks and voids then formed and initiated the deterioration of the concrete and a loss in the strength of the concrete components [21].

It is worth noting that the mass loss rates in the 30\% POFA mixes were far lower than the OPC specimens. This might be due to a lower concentration of reactive compounds, like $\mathrm{CaO}$, which slowed the degradation process and prevented ettringite's creation, which would have caused the concrete to expand [23]. The replacement of cement with POFA resulted in a more remarkable performance for the concrete. For the exact dosages of WPFT fibers, the mass losses of the POFA mixes were 15.6, 10.5, 8.3, 5.8, 3.5, and 3.2\%, respectively. According to the findings, the incorporation of WPFT fibers and POFA led to the enhancement of concrete against acid attack and reduced spalling and mass loss.

\subsubsection{Strength Loss}

Figure 14 shows a comparison of the strength values among water-cured samples and specimens submerged in a $\mathrm{H}_{2} \mathrm{SO}_{4}$ solution for 365 days. The extensive immersion in the acid solution was thought to be the cause of the strength reduction in all mixes. It was discovered that as the amount of WPFT fibers in the concrete increased, the strength loss reduced, whereas the rate of strength loss was higher in the plain concrete mix. When comparing the OPC specimens to $30 \%$ POFA mixes, the loss was shown to be greater. For OPC mixes comprising $0,0.2,0.4,0.6,0.8$, and $1 \%$ WPFT fibers, values of 31.4, 27.5, $24.7,23.4,21.7$, and $20.8 \mathrm{MPa}$ were recorded as strength losses, respectively. For the same amounts of fiber, the losses in the strength of POFA mixes were recorded as 28.4, 25.4, 22.8, 21.7, 20.5, and 19.9 MPa.

Due to the good pozzolanic activity of POFA and a lower $\mathrm{CaO}$ content, the combined effect of WPFT fiber and 30\% POFA caused a minor rate of strength loss. This is because OPC's $\mathrm{CaO}$ content reacts with $\mathrm{POFA}$ 's reactive $\mathrm{SiO}_{2}$ during the hydration process, resulting the formation of additional products, which helps to enhance the acid resistance of the matrix [22]. The use of POFA, on the other hand, has permitted the production of concrete that is very resistant to acid attacks. The presence of WPFT fibers reduced the creation of fine cracks and specimen spalling due to their linking effect. As such, the reinforced specimens immersed in the acid solution maintained their ductile behavior with a similar mode of failure, almost identical to that of the water-cured materials under compressive loads. Nevertheless, the control specimens without any fibers were completely distorted, and their failure modes were not the same as typical of water-cured concrete. In addition, as shown in Figure 15, the obtained SLF values of OPC mixtures were slightly higher than those noted for POFA mixes after 12 months of exposure to the acid solution. This behavior can be explained as follows: Adding 30\% POFA to concrete specimens resulted in more $\mathrm{Ca}(\mathrm{OH})_{2}$ being consumed throughout the hydration procedure, resulting in secondary C-S-H gels in the matrix, which reduced the micro-sized void density in the matrix [25]. The lower SLF values of reinforced POFA mixes signify the positive interaction of POFA and WPFT fiber in enhancing concrete performance against acid attacks. 

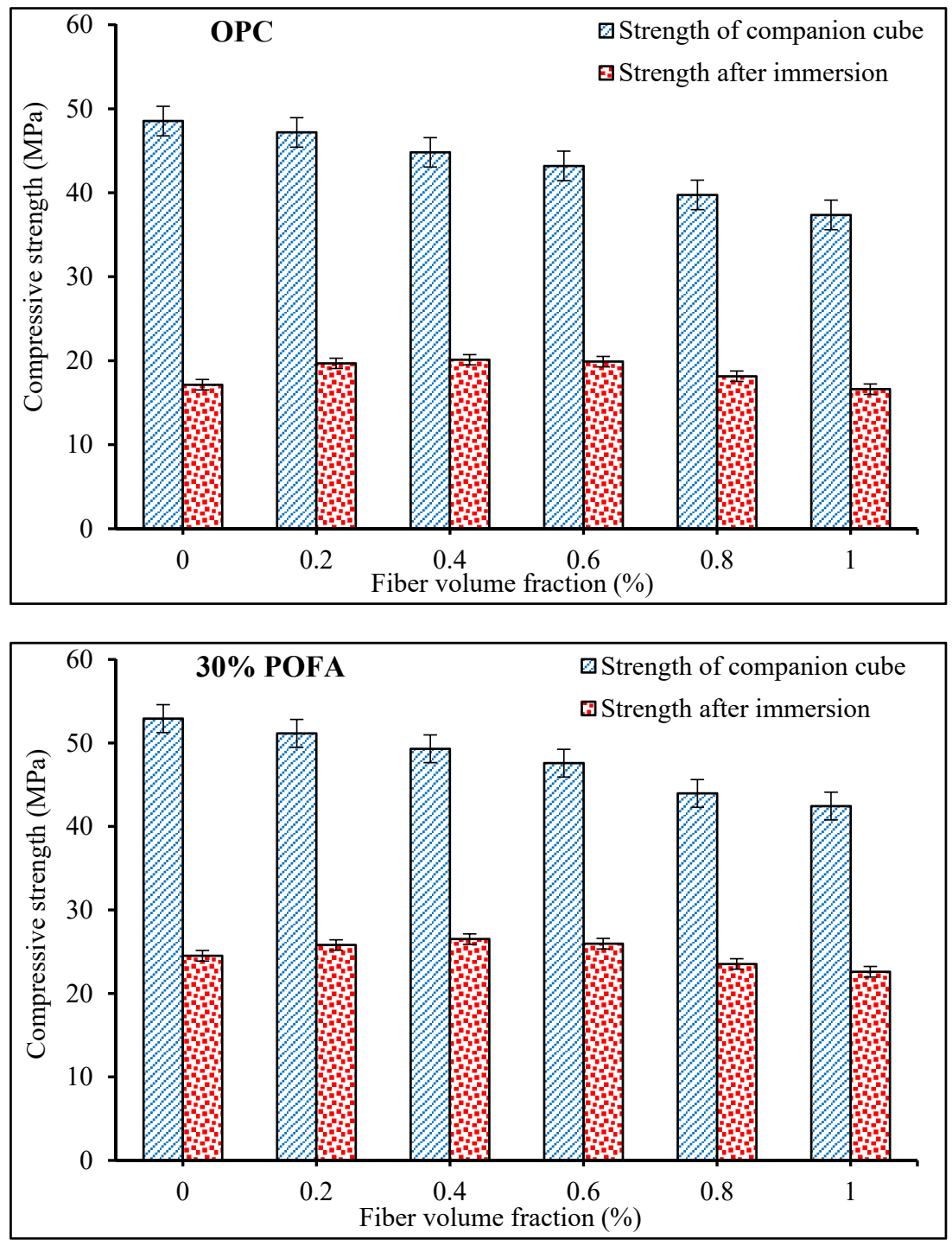

Figure 14. The variation in the 365-day compressive strength of concrete mixtures containing WPFT fibers exposed to a $\mathrm{H}_{2} \mathrm{SO}_{4}$ solution.

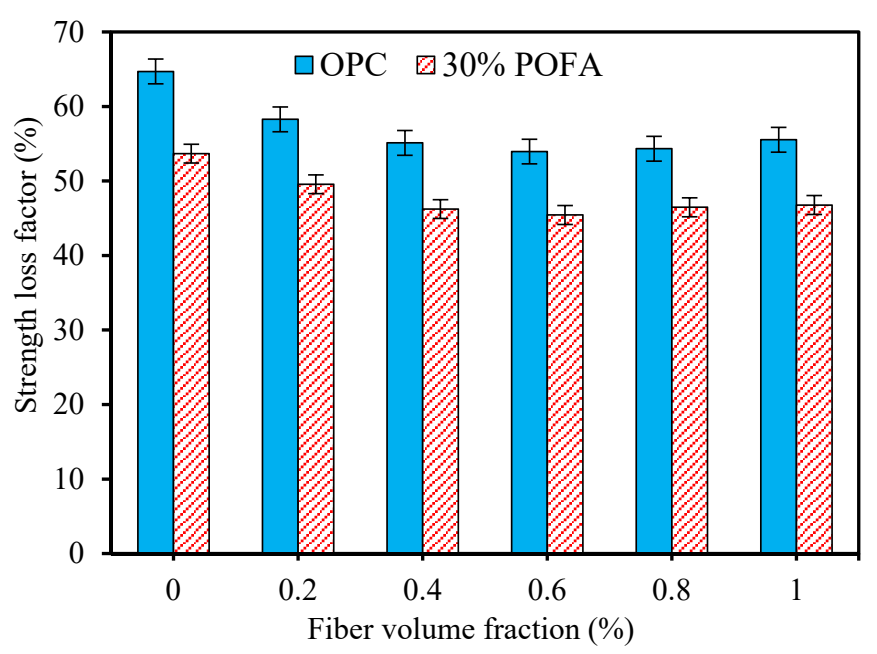

Figure 15. The effects of WPFT fibers on the strength loss factor of concrete mixtures exposed to a $\mathrm{H}_{2} \mathrm{SO}_{4}$ solution. 


\subsection{Scanning Electron Microscopy Analysis}

Chemical attacks are primarily manifested by losing strength and adherence rather than cracking and expansion. Figure 16 shows scanning electron microscopy (SEM) images of water-cured concrete samples and those immersed in $\mathrm{MgSO}_{4}$ and $\mathrm{H}_{2} \mathrm{SO}_{4}$ solutions for 365 days. Figure 16a shows the homogeneous spreading of C-S-H gel for watercured specimens after 365 days. The POFA-based mixes had enhanced performance under chemical attacks due to the consumption of $\mathrm{Ca}(\mathrm{OH})_{2}$ in high amounts, which is a soluble component in OPC during the pozzolanic reactions between POFA and OPC particles along the exposure period [22]. The SEM results of conventional OPC and POFA concrete mixtures treated with a $\mathrm{MgSO}_{4}$ solution are shown in Figure 16b. The SEM image demonstrates how the morphology of the matrix changed when immersed in a sulfate solution. The spherical pores in the OPC concrete mix gradually filled with more precipitated particles due to sulfate exposure. It can be detected that the pore volume of the OPC matrix varied during the exposure period, which affects both the mechanical properties and the durability of the concrete. Consequently, due to the pozzolanic activity of POFA and the development of extra C-S-H gel, the majority of the voids in the mixtures containing 30\% POFA filled up with these products, especially at later ages, leaving less space for the freshly harmful particles formed during the exposure period in the sulfate [41]. Accordingly, the strength and durability of concrete improved with the addition POFA as partial cement replacement $[45,46]$.

Besides, the microstructures of the OPC and POFA samples after 12 months of exposure to a severe $\mathrm{H}_{2} \mathrm{SO}_{4}$ solution are shown in Figure 16c. The production of gypsum at a high level can be seen in the OPC specimens. In the POFA matrix, the generation of gypsum was marginally lower. This was attributed to the existence of a greater amount of $\mathrm{Ca}(\mathrm{OH})_{2}$ particles in the OPC, which caused the formation of a soluble product such as gypsum in the matrix. Generally, gypsum with a weak structure is the main product of a chemical reaction between sulfuric acid and cement particles, which causes the specimen to expand and split [36]. During the hydration process, the $\mathrm{Ca}(\mathrm{OH})_{2}$ in the POFA matrix was consumed, generating C-S-H gels, which have a greater ability to resist acid attacks. Besides, the reactions between other components of OPC, such as calcium aluminate and gypsum, may result in the creation of ettringite, which expands the specimens and contributes to the formation of more cracks $[47,48]$.

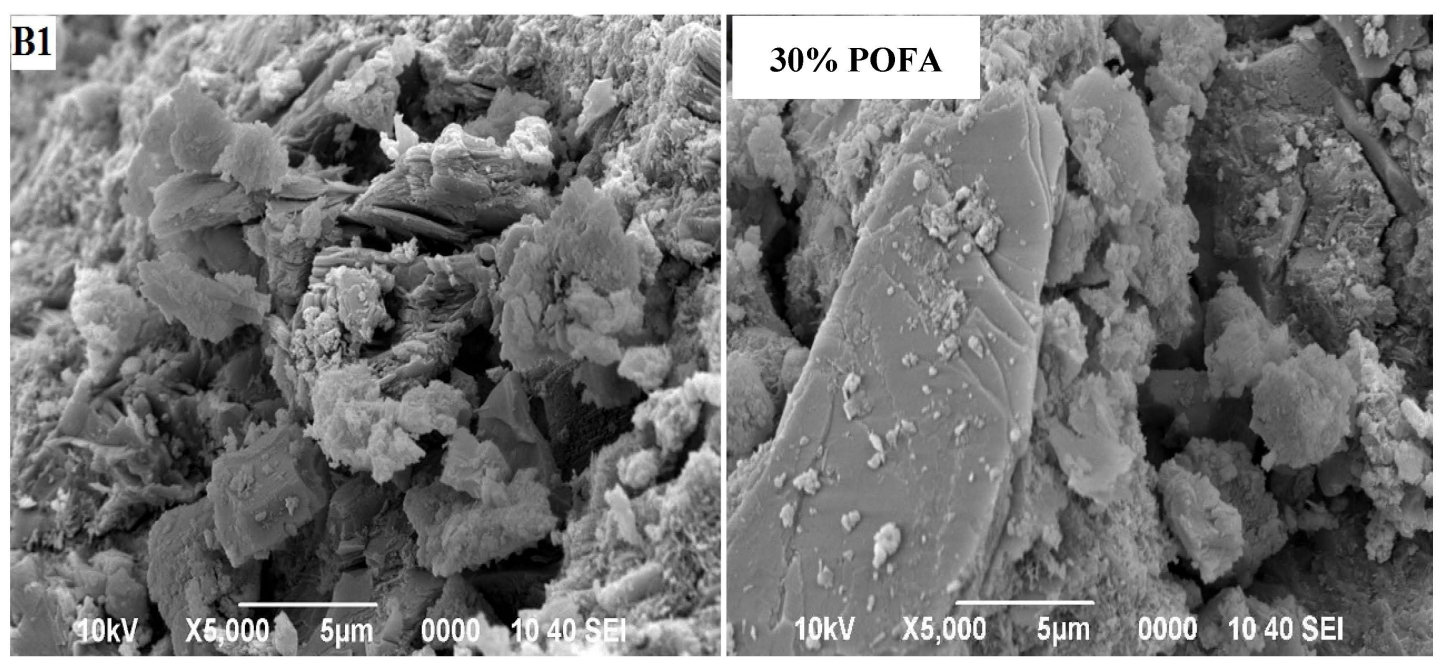

(a)

Figure 16. Cont. 


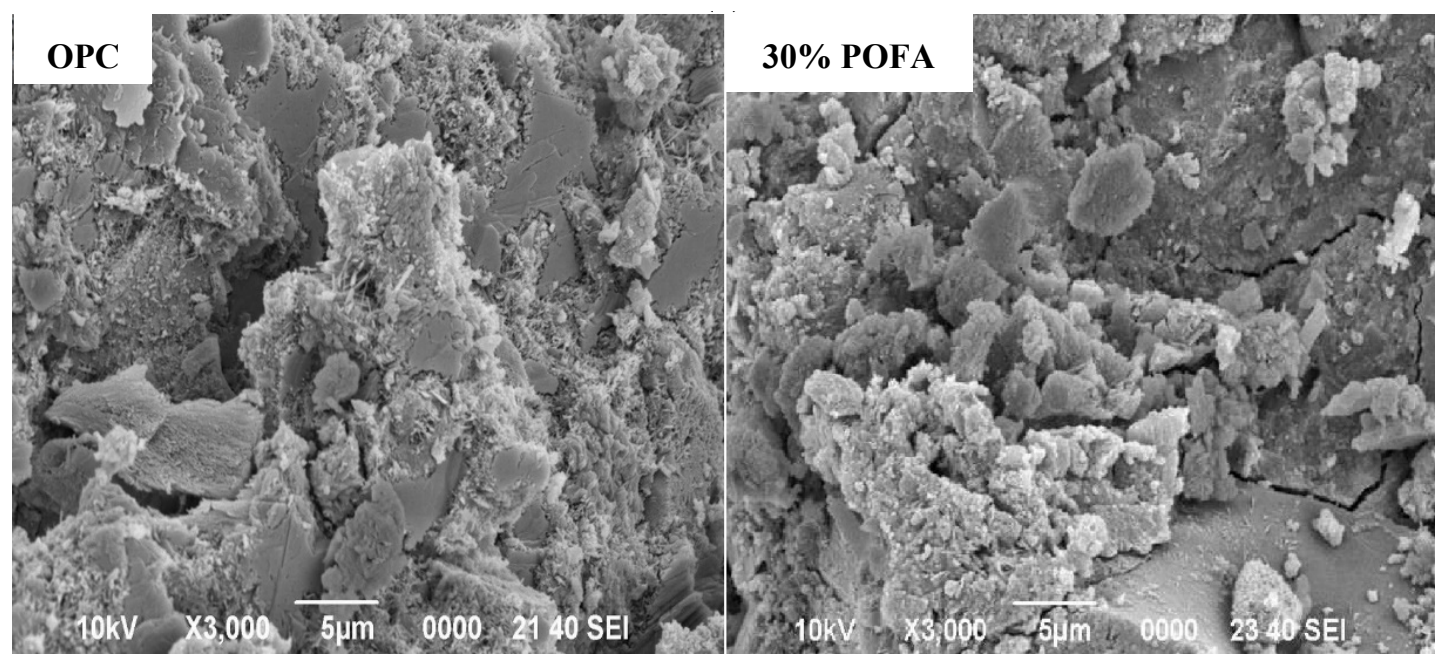

(b)

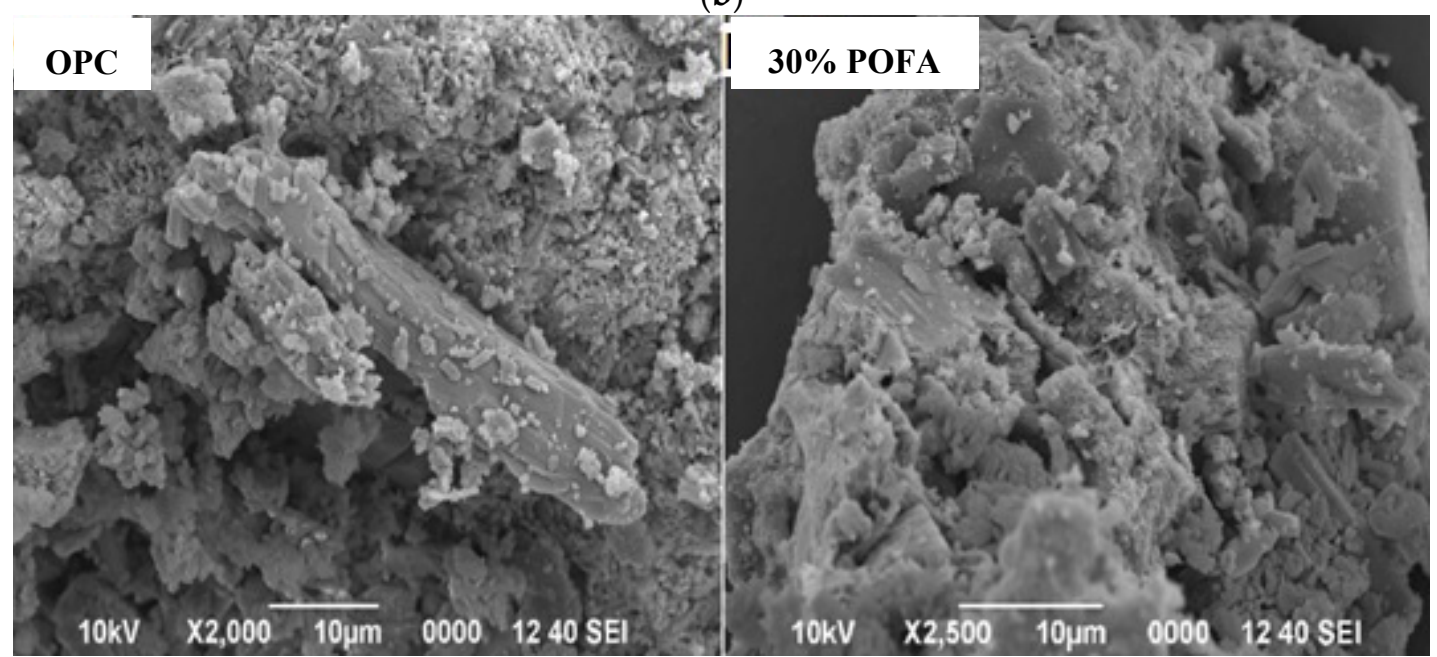

(c)

Figure 16. SEM images of plain OPC and POFA matrices at 12 months of exposure in (a) water, (b) $\mathrm{MgSO}_{4},(\mathbf{c})$ and $\mathrm{H}_{2} \mathrm{SO}_{4}$ solutions.

\section{Conclusions}

The long-term performance of concrete comprising WPFT fibers and POFA was investigated against sulfate and acid attacks after 365 days. Concrete specimens were exposed to $10 \% \mathrm{MgSO}_{4}$ and $5 \% \mathrm{H}_{2} \mathrm{SO}_{4}$ solutions. The performance of the concrete mixtures was assessed with the help of visual inspection, mass change, residual strength, and microstructural analysis. In the light of attained outcomes, the following conclusions can be drawn:

- Adding WPFT fibers into the concrete mixture resulted in a reduction in workability. The addition of $1 \%$ fibers resulted in a slump value of $35 \mathrm{~mm}$, which is comparatively lower than that of the $185 \mathrm{~mm}$ which was obtained for plain concrete mix.

- The compressive strength reduced as the fiber dosage increased. Initially, the strength improvement of POFA mixes was essentially identical to that of OPC concrete mixes. POFA-based concrete mixtures had higher compressive strength than OPC concrete mixtures after extended curing times. At 365 days, the obtained compressive strength values for POFA concrete mixes ranged from $42 \mathrm{MPa}$ to $52.9 \mathrm{MPa}$, which is higher than the values reported for OPC mixes. POFA's pozzolanic activity, which produces additional hydration products, can account for the higher strength values in POFA mixes.

- After being exposed to acid, the mass variation of plain and reinforced concrete specimens was negative, whereas the mass variation of sulfate-treated samples was 
positive. The rate of mass change in mixtures comprising WPFT fiber and POFA, on the other hand, was lower than that in the OPC combinations. Adding WPFT fibers to concrete exposed to chemical attacks was a good technique for controlling mass changes. The mass loss of POFA concrete specimens reinforced with $1 \%$ fibers after 12 months of exposure in the $\mathrm{H}_{2} \mathrm{SO}_{4}$ solution was recorded as $3.5 \%$, which is comparatively lower than that of the $15.5 \%$ recorded for the plain concrete without fibers.

- $\quad$ Adding WPFT fibers and POFA to concrete specimens improved their sulfate resistance. Due to the bridging action, the presence of WPFT fibers reduced expansion and crack development, whereas the control specimen expanded due to the high calcium oxide content in the sulfate solution. Consequently, a concrete mixture containing $0.4 \%$ WPFT fibers and 30\% POFA exposed to sulfate has excellent potential for reducing compressive strength loss to only $3.7 \mathrm{MPa}$.

- Concrete specimens containing POFA and WPFT fibers showed a respectable level of acid resistance. Concrete's acid resistance rose as the fiber volume percentage grew. It was discovered that concrete comprising 1\% WPFT fibers and 30\% POFA had a compressive strength loss of $19.9 \mathrm{MPa}$, which is comparatively lesser than that of the 31.4 MPa noted for the control mix.

- Due to the increased $\mathrm{CaO}$ content in ordinary Portland cement, the deterioration of OPC-based concrete mixtures was more severe and quicker than that of the POFA mixtures exposed to aggressive environments.

- $\mathrm{SEM}$ analysis of the pastes treated with $10 \% \mathrm{MgSO}_{4}$ and $5 \% \mathrm{H}_{2} \mathrm{SO}_{4}$ solutions revealed how the specimens changed in these harsh conditions. As a result of exposure, the pores of the OPC matrix eventually filled up with other precipitated elements. Furthermore, in the POFA mixtures, most voids were filled with these products due to POFA's pozzolanic action and additional C-S-H gel, especially at later ages, which developed the performance of the concrete.

- Concrete made from waste plastic food tray fibers and palm oil fuel could be commercialized and used to develop industrial structures and other similar uses where high resistance to harsh environments is required.

Author Contributions: All authors contributed to the paper evenly. Conceptualization, H.M. and R.A.; methodology, H.M. and R.A.; software H.M., S.P.N. and R.A.; validation, H.M. and R.A.; formal analysis, H.M. and R.A.; investigation, H.M. and R.A.; resources, H.M. and R.A.; data curation, H.M., S.P.N. and R.A.; writing—original draft preparation, H.M., M.M.T. and R.A.; writing—review and editing, H.M. and R.A.; visualization, H.M., S.P.N. and R.A.; supervision, M.M.T.; project administration, R.A. and S.P.N.; funding acquisition, H.M. and R.A. All authors have read and agreed to the published version of the manuscript.

Funding: This research was funded by University of Technology Malaysia under Postdoctoral fellowship grants.

Data Availability Statement: The data presented in this study are available on request from the corresponding author. The data are not publicly available due to the size of the research.

Acknowledgments: The authors would like to acknowledge the financial and technical supports received from Universiti Teknologi Malaysia and Prince Sattam Bin Abdulaziz University (Saudi Arabia).

Conflicts of Interest: The authors declare no conflict of interest.

\section{References}

1. Gu, L.; Ozbakkaloglu, T. Use of recycled plastics in concrete: A critical review. Waste Manag. 2016, 51, 19-42. [CrossRef]

2. Wu, S.; Montalvo, L. Repurposing waste plastics into cleaner asphalt pavement materials: A critical literature review. J. Clean. Prod. 2020, 280, 124355. [CrossRef]

3. Eriksen, M.; Christiansen, J.; Daugaard, A.E.; Astrup, T. Closing the loop for PET, PE and PP waste from households: Influence of material properties and product design for plastic recycling. Waste Manag. 2019, 96, 75-85. [CrossRef]

4. Hearn, G.; Ballard, J. The use of electrostatic techniques for the identification and sorting of waste packaging materials. Resour. Conserv. Recycl. 2005, 44, 91-98. [CrossRef] 
5. Blanco, I. Lifetime prediction of food and beverage packaging wastes. J. Therm. Anal. Calorim. 2016, 125, 809-816. [CrossRef]

6. Silvestre, C.; Duraccio, D.; Cimmino, S. Food packaging based on polymer nanomaterials. Prog. Polym. Sci. 2011, 36, 1766-1782. [CrossRef]

7. Martino, V.; Ruseckaite, R.; Jiménez, A. Thermal and mechanical characterisation of plasticised poly (L-lactide-co-D, L-lactide) films for food packaging. J. Therm. Anal. Calorim. 2006, 86, 707-712. [CrossRef]

8. Mohammadhosseini, H.; Yatim, J.M.; Sam, A.R.M.; Awal, A.A. Durability performance of green concrete composites containing waste carpet fibers and palm oil fuel ash. J. Clean. Prod. 2017, 144, 448-458. [CrossRef]

9. Alqahtani, F.K.; Abotaleb, I.S.; ElMenshawy, M. Life cycle cost analysis of lightweight green concrete utilizing recycled plastic aggregates. J. Build. Eng. 2021, 40, 102670. [CrossRef]

10. Mohammadhosseini, H.; Yatim, J.M. Microstructure and residual properties of green concrete composites incorporating waste carpet fibers and palm oil fuel ash at elevated temperatures. J. Clean. Prod. 2017, 144, 8-21. [CrossRef]

11. Hubo, S.; Leite, L.; Martins, C.; Ragaert, K. Evaluation of post-industrial and post-consumer polyolefin-based polymer waste streams for injection moulding. In Proceedings of the 6th Polymers \& Mould Innovations International Conference, Guimaraes, Portugal, 10-12 September 2014; pp. 201-206.

12. Kumar, S.; Panda, A.K.; Singh, R. A review on tertiary recycling of high-density polyethylene to fuel. Resour. Conserv. Recycl. 2011, 55, 893-910. [CrossRef]

13. Siddique, R.; Khatib, J.; Kaur, I. Use of recycled plastic in concrete: A review. Waste Manag. 2008, 28, 1835-1852. [CrossRef] [PubMed]

14. Almeshal, I.; Tayeh, B.A.; Alyousef, R.; Alabduljabbar, H.; Mohamed, A.M.; Alaskar, A. Use of recycled plastic as fine aggregate in cementitious composites: A review. Constr. Build. Mater. 2020, 253, 119146. [CrossRef]

15. Alyousef, R.; Mohammadhosseini, H.; Alrshoudi, F.; Alabduljabbar, H.; Mohamed, A.M. Enhanced performance of concrete composites comprising waste metalised polypropylene fibres exposed to aggressive environments. Crystals. 2020, 10, 696. [CrossRef]

16. Mohammadhosseini, H.; Alyousef, R.; Tahir, M.M. Towards Sustainable Concrete Composites through Waste Valorisation of Plastic Food Trays as Low-Cost Fibrous Materials. Sustainability. 2021, 13, 2073. [CrossRef]

17. Alrshoudi, F.; Mohammadhosseini, H.; Alyousef, R.; Alabduljabbar, H.; Mustafa Mohamed, A. The impact resistance and deformation performance of novel pre-packed aggregate concrete reinforced with waste polypropylene fibres. Crystals. 2020, 10, 788. [CrossRef]

18. Mohammadhosseini, H.; Ngian, S.P.; Alyousef, R.; Tahir, M.M. Synergistic effects of waste plastic food tray as low-cost fibrous materials and palm oil fuel ash on transport properties and drying shrinkage of concrete. J. Build. Eng. 2021, 42, 102826. [CrossRef]

19. Jain, A.; Siddique, S.; Gupta, T.; Jain, S.; Sharma, R.K.; Chaudhary, S. Evaluation of concrete containing waste plastic shredded fibers: Ductility properties. Struct. Concr. 2021, 22, 566-575. [CrossRef]

20. Colangelo, F.; Cioffi, R.; Liguori, B.; Iucolano, F. Recycled polyolefins waste as aggregates for lightweight concrete. Compos. Part B Eng. 2016, 106, 234-241. [CrossRef]

21. Sotiriadis, K.; Nikolopoulou, E.; Tsivilis, S. Sulfate resistance of limestone cement concrete exposed to combined chloride and sulfate environment at low temperature. Cem. Concr. Compos. 2012, 34, 903-910. [CrossRef]

22. Mohammadhosseini, H.; Tahir, M.M.; Sam, A.R.M.; Lim, N.H.A.S.; Samadi, M. Enhanced performance for aggressive environments of green concrete composites reinforced with waste carpet fibers and palm oil fuel ash. J. Clean. Prod. 2018, 185, 252-265. [CrossRef]

23. Bulatović, V.; Melešev, M.; Radeka, M.; Radonjanin, V.; Lukić, I. Evaluation of sulfate resistance of concrete with recycled and natural aggregates. Constr. Build. Mater. 2017, 152, 614-631. [CrossRef]

24. Wu, F.; Yu, Q.; Liu, C.; Brouwers, H.J.H.; Wang, L.; Liu, D. Effect of fibre type and content on performance of bio-based concrete containing heat-treated apricot shell. Mater. Struct. 2020, 53, 1-16. [CrossRef]

25. Neville, A. The confused world of sulfate attack on concrete. Cem. Concr. Res. 2004, 34, 1275-1296. [CrossRef]

26. Hill, J.; Byars, E.; Sharp, J.; Lynsdale, C.; Cripps, J.; Zhou, Q. An experimental study of combined acid and sulfate attack of concrete. Cem. Concr. Compos. 2003, 25, 997-1003. [CrossRef]

27. Hadigheh, S.A.; Gravina, R.; Smith, S. Effect of acid attack on FRP-to-concrete bonded interfaces. Constr. Build. Mater. 2017, 152, 285-303. [CrossRef]

28. Lu, C.; Zhou, Q.; Wang, W.; Wei, S.; Wang, C. Freeze-thaw resistance of recycled aggregate concrete damaged by simulated acid rain. J. Clean. Prod. 2021, 280, 124396. [CrossRef]

29. Mohammadhosseini, H.; Tahir, M.M. Durability performance of concrete incorporating waste metalized plastic fibres and palm oil fuel ash. Constr. Build. Mater. 2018, 180, 92-102. [CrossRef]

30. Bankir, M.B.; Sevim, U.K. Performance optimization of hybrid fiber concretes against acid and sulfate attack. J. Build. Eng. 2020, 32, 101443. [CrossRef]

31. Meng, C.; Li, W.; Cai, L.; Shi, X.; Jiang, C. Experimental research on durability of high-performance synthetic fibers reinforced concrete: Resistance to sulfate attack and freezing-thawing. Constr. Build. Mater. 2020, 262, 120055. [CrossRef]

32. Guo, L.; Wu, Y.; Xu, F.; Song, X.; Ye, J.; Duan, P.; Zhang, Z. Sulfate resistance of hybrid fiber reinforced metakaolin geopolymer composites. Compos. Part B Eng. 2020, 183, 107689. [CrossRef] 
33. Mohammadhosseini, H.; Alyousef, R.; Lim, N.H.A.S.; Tahir, M.M.; Alabduljabbar, H.; Mohamed, A.M.; Samadi, M. Waste metalized film food packaging as low cost and ecofriendly fibrous materials in the production of sustainable and green concrete composites. J. Clean. Prod. 2020, 258, 120726. [CrossRef]

34. Behfarnia, K.; Farshadfar, O. The effects of pozzolanic binders and polypropylene fibers on durability of SCC to magnesium sulfate attack. Constr. Build. Mater. 2013, 38, 64-71. [CrossRef]

35. Bolat, H.; Şimşek, O.; Çullu, M.; Durmuş, G.; Can, Ö. The effects of macro synthetic fiber reinforcement use on physical and mechanical properties of concrete. Compos. Part B Eng. 2014, 61, 191-198. [CrossRef]

36. Guo, X.; Xiong, G. Resistance of fiber-reinforced fly ash-steel slag based geopolymer mortar to sulfate attack and drying-wetting cycles. Constr. Build. Mater. 2021, 269, 121326. [CrossRef]

37. Turk, K.; Bassurucu, M.; Bitkin, R.E. Workability, strength and flexural toughness properties of hybrid steel fiber reinforced SCC with high-volume fiber. Constr. Build. Mater. 2021, 266, 120944. [CrossRef]

38. Li, K.; Yang, C.; Huang, W.; Zhao, Y.; Wang, Y.; Pan, Y.; Xu, F. Effects of hybrid fibers on workability, mechanical, and timedependent properties of high strength fiber-reinforced self-consolidating concrete. Constr. Build. Mater. 2021, $277,122325$. [CrossRef]

39. Bentegri, I.; Boukendakdji, O.; Kadri, E.-H.; Ngo, T.; Soualhi, H. Rheological and tribological behaviors of polypropylene fiber reinforced concrete. Constr. Build. Mater. 2020, 261, 119962. [CrossRef]

40. Mohammadhosseini, H.; Tahir, M.M.; Alaskar, A.; Alabduljabbar, H.; Alyousef, R. Enhancement of strength and transport properties of a novel preplaced aggregate fiber reinforced concrete by adding waste polypropylene carpet fibers. J. Build. Eng. 2020, 27, 101003. [CrossRef]

41. Alrshoudi, F.; Mohammadhosseini, H.; Alyousef, R.; Alghamdi, H.; Alharbi, Y.R.; Alsaif, A. Sustainable use of waste polypropylene fibers and palm oil fuel ash in the production of novel prepacked aggregate fiber-reinforced concrete. Sustainability. 2020, 12, 4871. [CrossRef]

42. Nili, M.; Afroughsabet, V. The effects of silica fume and polypropylene fibers on the impact resistance and mechanical properties of concrete. Constr. Build. Mater. 2010, 24, 927-933. [CrossRef]

43. Honglei, C.; Zuquan, J.; Penggang, W.; Jianhong, W.; Jian, L. Comprehensive resistance of fair-faced concrete suffering from sulfate attack under marine environments. Constr. Build. Mater. 2021, 277, 122312. [CrossRef]

44. Li, Y.; Yang, X.; Lou, P.; Wang, R.; Li, Y.; Si, Z. Sulfate attack resistance of recycled aggregate concrete with NaOH-solution-treated crumb rubber. Constr. Build. Mater. 2021, 287, 123044. [CrossRef]

45. Alrshoudi, F.; Mohammadhosseini, H.; Tahir, M.M.; Alyousef, R.; Alghamdi, H.; Alharbi, Y.; Alsaif, A. Drying shrinkage and creep properties of prepacked aggregate concrete reinforced with waste polypropylene fibers. J. Build. Eng. 2020, $32,101522$. [CrossRef]

46. Mohammadhosseini, H.; Lim, N.H.A.S.; Tahir, M.M.; Alyousef, R.; Samadi, M.; Alabduljabbar, H.; Mohamed, A.M. Effects of waste ceramic as cement and fine aggregate on durability performance of sustainable mortar. Arab. J. Scie. Eng. 2020, 45, 3623-3634. [CrossRef]

47. Mohammadhosseini, H.; Alrshoudi, F.; Tahir, M.M.; Alyousef, R.; Alghamdi, H.; Alharbi, Y.R.; Alsaif, A. Durability and thermal properties of prepacked aggregate concrete reinforced with waste polypropylene fibers. J. Build. Eng. 2020, 32, 101723. [CrossRef]

48. Mohammadhosseini, H.; Alrshoudi, F.; Tahir, M.M.; Alyousef, R.; Alghamdi, H.; Alharbi, Y.R.; Alsaif, A. Performance evaluation of novel prepacked aggregate concrete reinforced with waste polypropylene fibers at elevated temperatures. Constr. Build. Mater. 2020, 259, 120418. [CrossRef] 